\title{
Comparative genomics of transport proteins in developmental bacteria: Myxococcus xanthus and Streptomyces coelicolor
}

Ilya Getsin ${ }^{\dagger}$, Gina H Nalbandian ${ }^{\dagger}$, Daniel C Yee ${ }^{\dagger}$, Ake Vastermark, Philipp CG Paparoditis, Vamsee S Reddy and Milton H Saier Jr ${ }^{*}$

\begin{abstract}
Background: Two of the largest fully sequenced prokaryotic genomes are those of the actinobacterium, Streptomyces coelicolor (Sco), and the $\delta$-proteobacterium, Myxococcus xanthus (Mxa), both differentiating, sporulating, antibiotic producing, soil microbes. Although the genomes of Sco and Mxa are the same size ( 9 Mbp), Sco has $10 \%$ more genes that are on average 10\% smaller than those in Mxa.

Results: Surprisingly, Sco has 93\% more identifiable transport proteins than Mxa. This is because Sco has amplified several specific types of its transport protein genes, while Mxa has done so to a much lesser extent. Amplification is substrate- and family-specific. For example, Sco but not Mxa has amplified its voltage-gated ion channels but not its aquaporins and mechano-sensitive channels. Sco but not Mxa has also amplified drug efflux pumps of the DHA2 Family of the Major Facilitator Superfamily (MFS) (49 versus 6), amino acid transporters of the APC Family (17 versus 2), ABC-type sugar transport proteins (85 versus 6), and organic anion transporters of several families. Sco has not amplified most other types of transporters. Mxa has selectively amplified one family of macrolid exporters relative to Sco (16 versus 1), consistent with the observation that Mxa makes more macrolids than does Sco.

Conclusions: Except for electron transport carriers, there is a poor correlation between the types of transporters found in these two organisms, suggesting that their solutions to differentiative and metabolic needs evolved independently. A number of unexpected and surprising observations are presented, and predictions are made regarding the physiological functions of recognizable transporters as well as the existence of yet to be discovered transport systems in these two important model organisms and their relatives. The results provide insight into the evolutionary processes by which two dissimilar prokaryotes evolved complexity, particularly through selective chromosomal gene amplification.
\end{abstract}

Keywords: Transport proteins, Streptomyces, Myxococcus, Genome analyses

\section{Background}

Spore formation is common within the prokaryotic world. Endospores can be found in a variety of Gram-positive bacteria, including species of Bacillus, Clostridium, Metabacterium and Thermoactinomyces [1]. Aerial exospore formation is common among species of Streptomyces [2]. Dermatophilus form zoospores [3], while Azotobacter form resting cysts [4]. Myxospores are common among

\footnotetext{
* Correspondence: msaier@ucsd.edu

${ }^{\dagger}$ Equal contributors

Department of Molecular Biology, University of California at San Diego, La Jolla, CA 92093-0116, USA
}

the Myxobacteria, including species of Myxococcus and Stigmatella [5]. Other resting cell types can be found in cyanobacteria such as Anabaena [6]. The best characterized of the sporulation processes is endospore formation in Bacillus subtilis [7]. However, aerial mycelial exospores in actinobacteria and fruiting body bearing myxospores in myxobacteria provide alternatives for understanding the molecular bases of complex multicellular prokaryotic differentiation.

The two organisms that serve as model systems to represent these two phyla are Streptomyces coelicolor (Sco) and Myxococcus xanthus (Mxa). Both organisms

\section{Biomed Central}


interact and produce antibiotics and a variety of other secondary metabolites, rendering them important for medical and biotechnological purposes [8-10]. Some gene families such as regulatory gene families are amplified; for example, Sco has $44 \mathrm{ser} / \mathrm{thr}$ protein kinases and Mxa has 97, although most bacteria have only $0-3$. The genomes of these two organisms have been fully sequenced, and they prove to be among the largest prokaryotic genomes currently available for analysis, both being about 9 million base pairs (Mbp) in size $[11,12]$. Because of the unique features of these two organisms, we have conducted a thorough investigation of the transport proteins encoded within their genomes.

Transport proteins serve as important mediators of communication between the cell cytoplasm and the extracellular environment [13]. They frequently allow transmission of signals that determine transcription patterns and progression into programs of differentiation [14]. They also determine whether or not secondary metabolites such as antibiotics will be synthesized, exported, or imported [15]. We have therefore initiated a study to determine what transporters are likely to be important for these processes and whether or not these two complex organisms share these systems.

In this paper, we analyze the genomes of Sco and Mxa for all integral membrane transport proteins that correspond to currently recognized transporters included within the Transporter Classification Database TCDB; www.tcdb. org; [16-18]. These systems fall into several classes, including (1) channels/pores, (2) secondary carriers, (3) primary active transporters, (4) group translocators, (5) transmembrane electron flow carriers, (8) auxiliary transport proteins, and (9) transporters of unknown mechanism of action. The identified proteins are analyzed by class, topology and substrate specificity, and the results are compared.

Our analyses reveal that these two organisms use fundamentally different systems to transport various substrates, suggestive of independent evolution. While Sco has amplified the numbers of transporters in certain families specific for certain types of substrates (e.g. sugars, amino acids, organic anions), Mxa has not. Moreover, they use very different types of transporters for the purpose of extruding antimicrobial agents. The results lead to the conclusion that Sco and Mxa have used very different strategies to create programs of differentiation and solve metabolic problems created by the development of multiple cell types.

\section{Results}

\section{Streptomyces coelicolor (Sco) Transporters}

For the purpose of genome analyses, we classify transport systems according to the IUBMB-approved Transporter Classification (TC) System. Transporters fall into five well-defined categories (Classes 1 to 5) and two poorly defined categories (Classes 8 and 9) as mentioned above, (see TCDB; www.tcdb.org; [13,18-20]). Additional file 1: Table S1 and Figure 1 present an overall summary of the classes and subclasses of transporters found in Streptomyces coelicolor (Sco). Only integral membrane transport proteins, mostly those that provide the transmembrane pathway for solute translocation, are reported. We identified 658 such proteins encoded in the Sco genome. The entire genome is 9.05 million base pairs and is reported to encode 7825 proteins [11]. Thus, $8.1 \%$ of the proteins encoded within the genome of Sco are recognized integral membrane transport proteins. Functionally characterized and partially characterized transporters reported in the literature are tabulated and discussed below (see section entitled "Transporters of experimentally verified function in Sco and Mxa”).

\section{Types of transporters in Sco}

Sco encodes representatives within the major classes of transport proteins included in TCDB, and their distributions are summarized here (see Table 1): 20 (3\%) of these proteins are simple channels; 277 (41\%) are secondary carriers; 321 (49\%) are primary active transport proteins; 7 (1\%) are group translocators; 9 (1\%) are transmembrane electron flow carriers; $4(0.6 \%)$ are auxiliary transport proteins, and $20(3 \%)$ are of unknown mechanism of action. Thus, primary and secondary active transporters are of about equal importance in Sco while other defined types of transporters are much less important.

Of the channel type proteins, almost all are alpha-type channels (Subclass 1.A), presumably in the cytoplasmic membrane. No outer membrane porins (Subclass 1.B) were identified, probably because actinobacteria have porins that differ from those in Gram-negative bacteria, and few of these have been characterized [21-25]. Those known for Mycobacteria, Nocardia and Corynebacteria do not have homologues in Streptomyces that are sufficiently similar to be recognized. A single putative channel-forming toxin (Subclass 1.C) (belonging to the BAPA Family; TCID number 1.C.42.1.1) was detected.

Secondary carriers (Subclass 2.A) and primary active transporters (mostly ATP-dependent (Subclass 3.A)) represent the majority of the transporters, but a smaller percentage are decarboxylation driven (Subclass 3.B) or oxidoreduction driven (Subclass 3.D) primary active transporters. Among the seven group translocation proteins, five belong to the phosphotransferase system (Subclass 4.A), one may be a nicotinamide ribonucleoside uptake system (Subclass 4.B), and another may be an acyl CoA ligase-coupled transporter (Subclass 4.C). Nine proteins possibly function as transmembrane electron flow carriers with eight of them carrying electron pairs (Subclass 5.A), while one may be a single electron carrier (Subclass 5.B). 


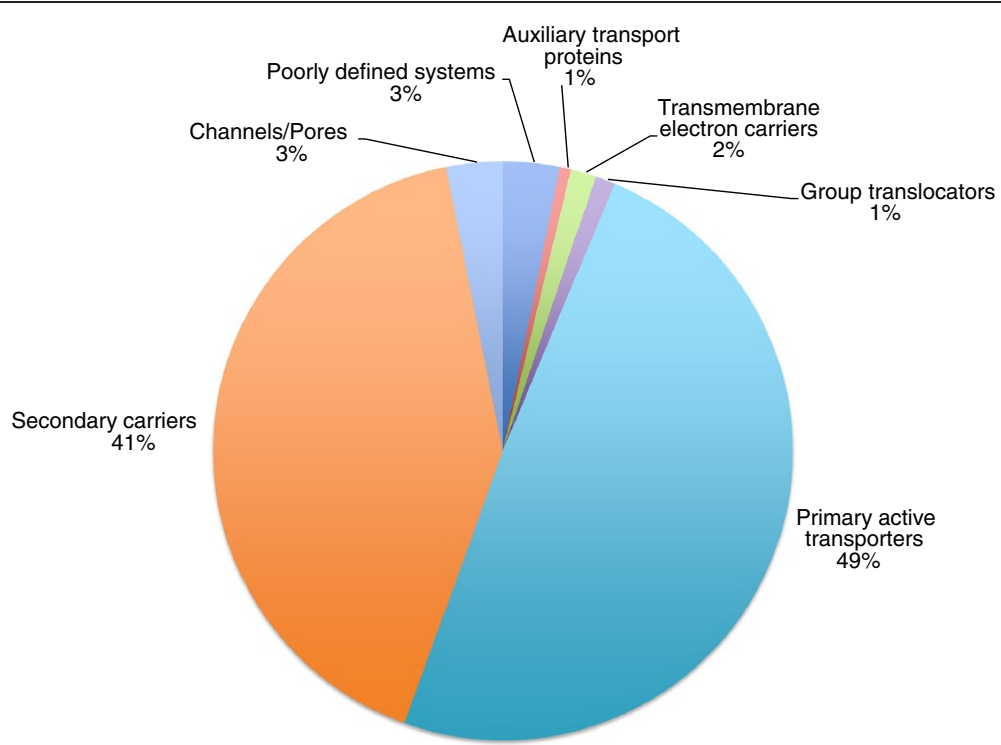

Figure 1 Streptomyces coelicolor transporter type percentages. Transporter type percentages in Streptomyces coelicolor, based on the Transporter Classification (TC) system.

\section{Substrates transported by Sco}

Table 2 presents numbers of transport proteins in Sco categorized according to substrate. Transporters that function with inorganic molecules as substrates can be nonselective or can exhibit selectivity toward cations or anions. Almost all nonselective transporters are channels (see Additional file 1: Table S1 and Figure 2). A large majority of cation transporters $(13.9 \%-89$ total $)$ are either primary active transporters (33 proteins) or secondary carriers (32 proteins). However, the remaining cation transporters are either channels (9 proteins) or poorly defined systems (15 proteins). Of the inorganic

Table 1 Numbers of Sco transport proteins according to TC class and subclass

\begin{tabular}{|c|c|c|c|c|c|}
\hline $\begin{array}{l}\mathrm{TC} \\
\text { class }^{\mathrm{a}}\end{array}$ & Class description & $\begin{array}{l}\text { No. of } \\
\text { proteins }\end{array}$ & $\begin{array}{c}\text { TC } \\
\text { subclass }\end{array}$ & Subclass description & $\begin{array}{c}\text { No. of } \\
\text { proteins }\end{array}$ \\
\hline \multirow[t]{3}{*}{1} & Channel/Pore & 20 & 1.A & a-type channel & 19 \\
\hline & & & $1 . \mathrm{B}$ & $\beta$-type porin & 0 \\
\hline & & & 1.C & Pore-forming toxin & 1 \\
\hline 2 & Secondary carrier & 277 & 2.A & Porter (uniporter, symporter, antiporter) & 277 \\
\hline \multirow[t]{4}{*}{3} & Primary active transporter & 321 & 3.A & P-P-bond hydrolysis-driven transporter & 286 \\
\hline & & & 3.B & Decarboxylation-driven transporter & 4 \\
\hline & & & 3.D & Oxidoreduction-driven transporter & 28 \\
\hline & & & 3.E & Light absorption-driven transporter & 3 \\
\hline \multirow[t]{3}{*}{4} & Group translocator & 7 & 4.A & Phosphotransfer-driven group translocator & 5 \\
\hline & & & $4 . B$ & Nicotinamide ribonucleoside uptake transporter & 1 \\
\hline & & & 4.C & Acyl CoA ligase-coupled transporter & 1 \\
\hline \multirow[t]{2}{*}{5} & $\begin{array}{l}\text { Transmembrane electron } \\
\text { carrier }\end{array}$ & 9 & 5.A & Transmembrane 2-electron transfer carrier & 8 \\
\hline & & & $5 . \mathrm{B}$ & Transmembrane 1-electron transfer carrier & 1 \\
\hline 8 & Auxiliary transport protein ${ }^{b}$ & 4 & $8 . \mathrm{A}$ & Auxiliary transport protein & 4 \\
\hline 9 & Poorly defined system & 20 & 9.A & $\begin{array}{c}\text { Recognized transporter of unknown biochemical } \\
\text { mechanism }\end{array}$ & 20 \\
\hline Total & & 658 & & & \\
\hline
\end{tabular}

Detailed class and subclass descriptions can be found at www.tcdb.org.

${ }^{a}$ Transporter classes 6 and 7 have not been assigned in the TC system yet and therefore are not listed here.

${ }^{\mathrm{b}}$ Auxiliary proteins facilitate transport via established transport systems and therefore are not counted as separate systems. 
Table 2 Counts of Sco transport proteins according to substrate type

\begin{tabular}{|c|c|c|c|c|c|c|c|c|}
\hline \multirow[t]{2}{*}{ Substrate } & \multicolumn{8}{|c|}{ No. of proteins of indicated type acting on substrate type } \\
\hline & $\begin{array}{l}\text { Channels/ } \\
\text { Pores }\end{array}$ & $\begin{array}{l}\text { Primary } \\
\text { Carriers }\end{array}$ & $\begin{array}{l}\text { Secondary } \\
\text { Carriers }\end{array}$ & $\begin{array}{c}\text { Group } \\
\text { translocators }\end{array}$ & $\begin{array}{l}\text { Transmembrane } \\
\text { electron flow } \\
\text { carriers }\end{array}$ & $\begin{array}{l}\text { Auxiliary } \\
\text { proteins }\end{array}$ & $\begin{array}{c}\text { (Putative) } \\
\text { Poorly } \\
\text { characterized }\end{array}$ & $\begin{array}{l}\text { Total no. } \\
\text { of systems }\end{array}$ \\
\hline
\end{tabular}

\section{Inorganic Molecules}

$\begin{array}{lccc}\text { A. Nonselective } & 5 & 1 \\ \text { B. Cations } & 9 & 33 & 32 \\ \text { C. Anions } & & 6 & 15 \\ \text { D. Electrons } & & 29 & 2\end{array}$

\section{1}

II. Carbon sources

A. Sugars \& polyols

2

83

$$
9
$$

B. Monocarboxylates

C. Di- \& tricarboxylates

D. Organoanions (noncarboxylic)

E. Aromatic Compounds

7

III. Amino acids \& their derivatives
A. Amino acids \& conjugates

$16 \quad 39$

7.
B. Amines, amides, polyamines, \& organocations
C. Peptides
IV. Vitamins, cofactors \& cofactor precursors
A. Vitamins \& vitamin or cofactor precursors
B. Enzyme \& redox cofactors
C. Siderophores; siderophore-Fe complexes

V. Drugs, dyes, sterols \& toxins
A. Multiple drugs
B. Specific drugs
C. Pigments
D. Other hydrophobic

$4 \quad 58$

$7 \quad 1$ substances

VI. Macromolecules
A. Carbohydrates
B. Proteins
C. Lipids

$\begin{array}{lll}1 & 16 \\ 1 & 10\end{array}$

16

10

14

7

1

3

18

17

VII. Nucleic acids

A. Nucleic acids

10

8

2

21

VIII. Unknown

\begin{tabular}{lcccccc} 
A. Unknown & 3 & 14 & & & \\
Total & 20 & 321 & 277 & 7 & 9 & 20 \\
\hline
\end{tabular}

Substrate categories include: (I) inorganic molecules; (II) carbon sources; (III) amino acids \& their derivatives; (IV) vitamins, cofactors \& cofactor precursors; (V) drugs, dyes, sterols \& toxins; (VI) macromolecules; (VII) nucleic acids; and (VIII) unknown. 


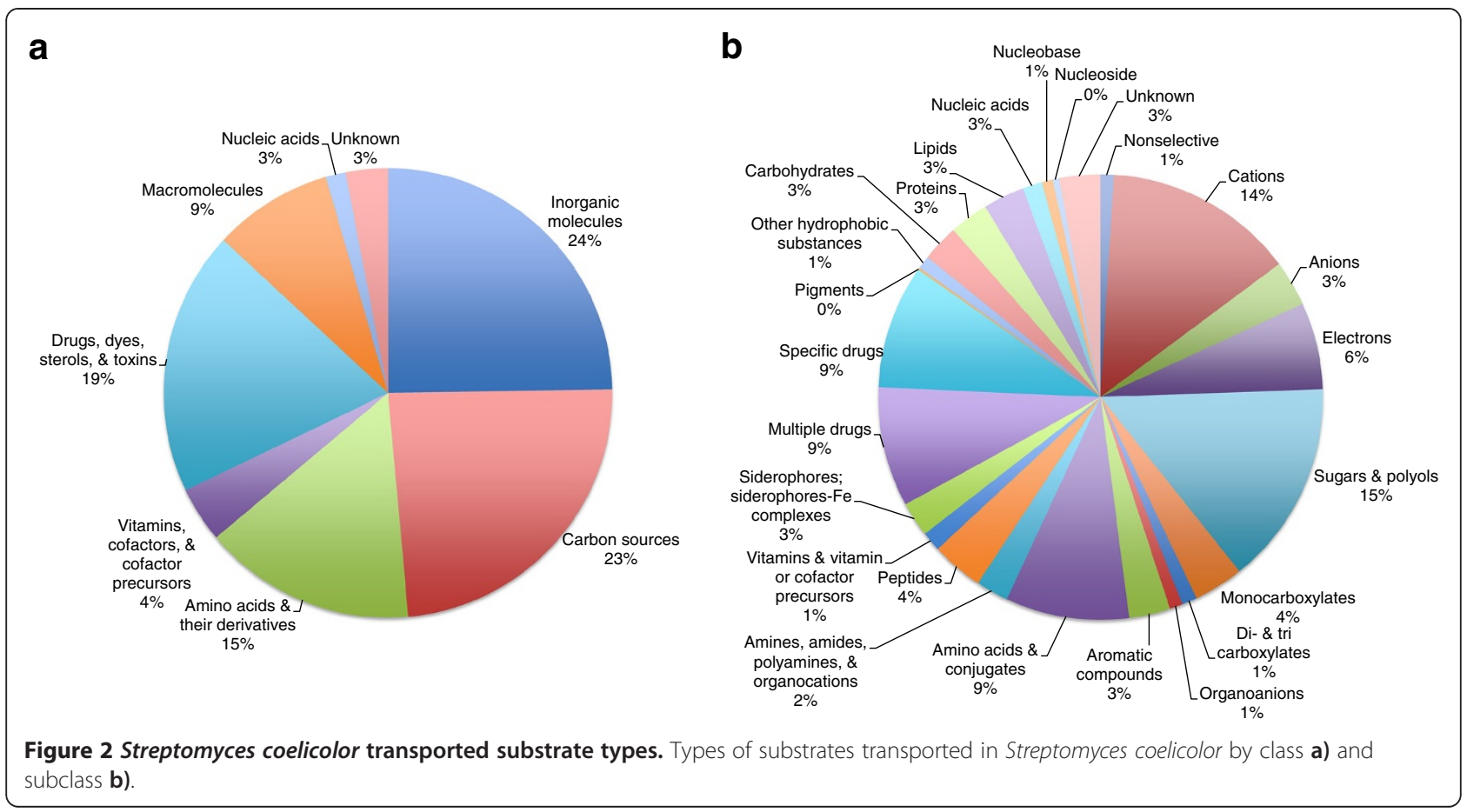

anion transporters $(3.3 \%-21$ total), 15 are secondary carriers and 6 are primary active transporters. Finally, for the electron transfer carriers $(6.3 \%-40$ total), a majority function as primary active ion pumps ( 29 proteins), while a smaller number of these systems are transmembrane electron flow carriers (9 proteins).

Of the carbon sources taken up by Sco, we find that the types of transporters used correlate with the type of energy generated by metabolism of these compounds. Thus, sugars \& polyols ( $14.8 \%$ - 96 total), normally metabolized via glycolysis, are transported largely by primary active $\mathrm{ABC}$-type transporters ( 83 proteins). Since these ATP-dependent porters usually exhibit higher affinities than secondary carriers, this suggests that sugars may be present in the soil environments of Streptomyces species at low concentrations. However, 9 secondary carriers, 2 channels, and 2 group translocators are specific for these molecules. PTS group translocators, like $A B C$ transporters, are usually high affinity systems that recognize their sugar substrates with micromolar or submicromolar affinities. Since they use phosphoenolpyruvate to energize uptake, the same arguments presented for $A B C$ transporters apply.

Monocarboxylates (3.6\% - 23 total) are transported by 15 secondary carriers and 11 primary active transporters. Di- \& tricarboxylates and aromatic compounds are transported solely by secondary carriers while noncarboxylic organoanions are mostly transported by secondary carriers. In summary, sugars are transported primarily by ATPdriven porters, while organic anionic compounds are transported primarily by pmf-driven carriers. This observation is in agreement with the primary energy source generated by the metabolism of these compounds (ATP from sugars; the pmf from organic acids).

Amino acids \& their derivatives are transported primarily by secondary carriers although peptides are taken up almost exclusively by ABC systems. Transporters for amino acids and conjugates (9\% - 56 total) include secondary carriers (39 proteins), primary active transporters (16 proteins), and a single channel. Amines, amides, polyamines \& organocations $(2.4 \%$ - 15 total) were found to be transported by both primary active transporters (5 proteins) and secondary carriers (7 proteins). They are also transported by two amino sugar uptake group translocators (both TC\# 4.A.1.1.5) and a channel protein (TC\# 1.A.11.1.3). With the exception of one secondary carrier (TC\# 2.A.17.1.1), almost all peptides (3.8\% - 21 total) are taken up or expelled by primary active transporters $(20$ proteins). Considered collectively, nitrogenous compounds are thus transported roughly equally by primary and secondary carriers.

Vitamins and especially iron siderophore complexes are primarily taken up via $\mathrm{ABC}$-type active transporters. Specifically, vitamins \& vitamin or cofactor precursors are taken up by primary active transporters (5 proteins), secondary carriers (3 proteins) and a single group translocator. Transporters for siderophores and siderophore-Fe complexes (29 total) are mostly primary active transporters (21 proteins), with fewer secondary carriers (8 proteins). This fact probably reflects the need for high affinity 
recognition due to the low concentrations of these substances in the external environment.

Transport of drugs and other hydrophobic substances occurs primarily by secondary pumps. Systems for multiple drugs $(8.7 \%$ - 56 total) are exported via secondary carriers (36 proteins) and primary active transporters (20 proteins), but almost all of the specific drug exporters (62 total) are secondary carriers (58 proteins), with only four exceptional primary active transporters. By contrast, of the 8 pigment exporters identified [26,27], 7 proved to be primary carriers. All other systems specific for hydrophobic substances are primary active transporters.

Macromolecular transporters can be specific for complex carbohydrates, proteins, nucleic acids or lipids. Almost all systems specific for complex carbohydrates (2.7\% - 18 total) are primary active transporters, and more than half of the protein and ligand secretion systems are primary active transporters. Nucleic acid precursor transporters fall into several classes and subclasses, with about equal numbers of primary and secondary carriers.

\section{Superfamily representation in Sco}

Examination of the superfamilies represented in Sco revealed that of the transmembrane proteins, the largest proportion of these proteins falls into the $A B C$ Functional Superfamily (39\% - 249 proteins), which includes three independently evolving families of integral membrane proteins [28]. The Major Facilitator Superfamily (MFS) of secondary carriers (18\% - 114 proteins) is the second most represented superfamily. The next largest superfamily is the APC Superfamily, which includes 6\% of the transmembrane porters (32 proteins). The RND and DMT superfamilies (16 and 17 proteins respectively) both contain about 3\% of the transporters, while the P-ATPase, CDF, and CPA superfamilies each encompass roughly $2 \%$. Additional superfamilies that each encompass approximately $1 \%$ of the porters include the VIC, BART, IT, PTS-GFL, and COX Superfamilies (see TCDB for further explanation).

\section{Topological analyses of Sco transporters}

Sco transport proteins were examined according to predicted topology (Figure 3). The topologies of all proteins included in our study are presented in Figure 3a. Except for the 1 transmembrane segment (TMS) proteins (largely ABC-type extracytoplasmic solute receptors with a single N-terminal signal TMS), proteins with even numbers of TMSs outnumber proteins with odd numbers of TMSs, with the 6 and 12 TMS proteins predominating. For the few channel proteins (Class 1), 2 and 4 TMS proteins are most numerous, but for carriers (Class 2; primarily MFS carriers) and primary active transporters (Class 3; primarily ABC porters), 12 and 6 TMS proteins predominate, respectively. These are equivalent considering that MFS permeases are functionally monomeric while $A B C$ systems are most frequently dimeric. The evolutionary explanations for these topological observations in transporters have been discussed previously [29].

\section{Distribution of transport protein genes within the Sco genome}

Bentley et al. [11] reported that the S. coelicolor genome is divided into three parts: arm1 ( 0 - 1.5 Mbp), arm2 ( 6.4 $8.67 \mathrm{Mbp})$, and the core ( 1.5 - 6.4 Mbp). We therefore examined these three segments of the chromosome to see if the transport protein-encoding genes for any of the well represented (sub)families tended to localize to one of these regions. The results are presented in Additional file 2: Table S2. In general, the proteins of any one (sub)family are distributed fairly equally between these three segments with few exceptions.

Arm1 includes $17 \%$ of the total chromosome and encodes $16 \%$ of the transport proteins. The core includes $57 \%$ of the chromosome and encodes $54 \%$ of the transport proteins. Arm 2 includes $26 \%$ of the chromosome and encodes $30 \%$ of the transport proteins. Thus, transporter genes exhibit nearly uniform density within the three chromosomal segments.

Three (sub)families (2.A.1.67, 2.A.39 and 3.A.1.3) have five members in $S$. coelicolor. The distributions of the encoding genes within arm1, arm2, and core are 0/1/4, $1 / 2 / 2$ and 0/0/5. Subfamily 3.A.1.3 is concerned exclusively with the uptake of polar amino acids and therefore probably serves housekeeping functions. Five subfamilies have six proteins, and all but one are represented in all three chromosomal segments. Two subfamilies have seven proteins and two have eight. All four are also represented in all three segments. Two subfamilies (3.A.1.2 and 3.A.1.105) have ten members, and while the former has representation in all three segments, the latter has all ten genes in the core. These proteins catalyze drug export. Subfamily 2.A.1.2 has eleven members distributed throughout the chromosome. Two (sub)families have seventeen members. Family 2.A.3 amino acid uptake porters and subfamily 3.A.1.5 peptide and oligosaccharide uptake systems are distributed about equally on arm 2 and the core with little or no representation on arm1. Finally, the 45 members of the MFS polar amino acid porters (subfamily 2.A.1.3) show equal representation in arm 2 and the core, but poor representation in arm1. Conversely, ABC sugar transporters of subfamily of 3.A.1.1 with 75 members have nearly equal distribution in the three chromosomal segments. In this case the gene density is somewhat highest on arm1.

These results show that while the transporters in general are distributed in accordance with expectation based on the sizes of these segments, some (sub)families are 


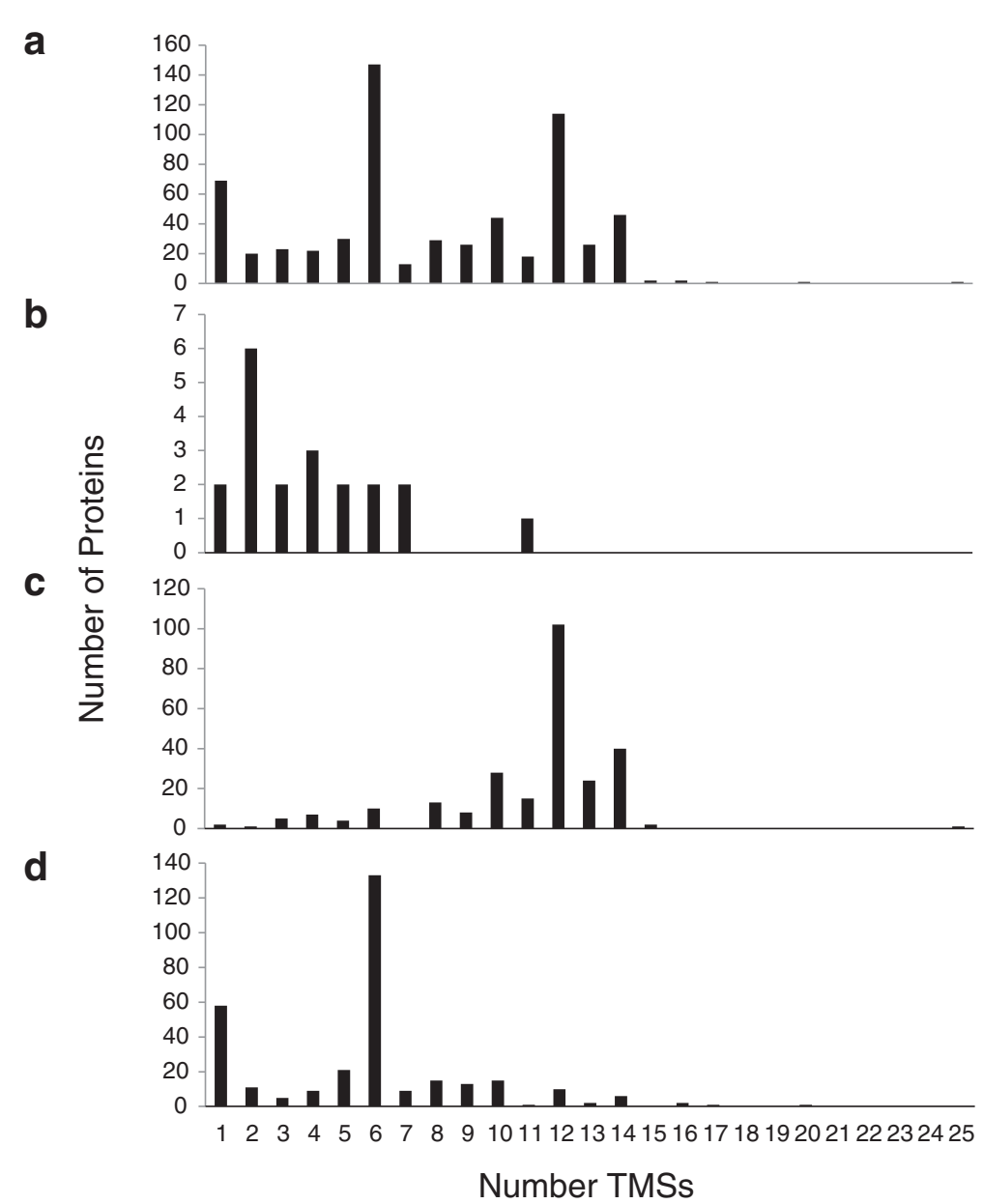

Figure 3 Streptomyces coelicolor transport protein topologies. Transport protein topologies for all proteins a), channels b), secondary carriers c) and primary active transporters d) in Streptomyces coelicolor.

asymmetrically distributed. However, seldom are the members of a single (sub)family localized to a single segment.

\section{Identification of distant transport proteins in Sco}

In the analyses reported above, the cutoff point for proteins retrieved using the GBLAST program was an e-value of 0.001 . In order to determine if more distant transport protein homologues could be identified, all sequences brought up with e-values between 0.001 and 0.1 were examined. In Sco, over 300 sequences were retrieved, almost all of which proved to be false positives. However, careful examination revealed that a few true transport protein homologues were included in this list. The following 14 proteins, all of which have been included in TCDB, were obtained (see Table 3).

Two proteins (Q9KXM8 and Q9KYD4) were 12 TMS proteins that proved to be members of the Drug: $\mathrm{H}^{+}$ Antiporter-3 (DHA3) Family within the Major Facilitator Superfamily (MFS). These 2 proteins were assigned TC numbers 2.A.1.21.18 and 2.A.1.21.19. A third protein proved to belong to the Cation Diffusion Facilitator (CDF) Family. This protein (Q9X897; 234 aas; 6 TMSs) was assigned to a new CDF Subfamily, TC\# 2.A.4.8.1. A homologue (Q9RD35; 238 aas; 6 TMSs) was so similar to its paralogue, Q9X897 (83\% identity and 90\% similarity with 1 gap), that it was not entered into TCDB. A fifth protein (O86513; 334 aas; 9TMSs) proved to belong to the Drug Metabolite Exporter (DME) Family within the Drug Metabolite Transporter (DMT) Superfamily and was assigned TC\# 2.A.7.3.43. A sixth protein (Q9KY69; 338 aas; 10 TMSs) was shown to belong to the Telurite-resistance/Dicarboxylate Transporter (TDT) Family and was assigned TC\# 2.A.16.4.6. Finally, a seventh protein (Q9RJJ1; 429 aas; 12 TMSs) defined a new family within the Multi-drug Oligosaccharide-lipid/ Polysaccharide (MOP) Flippase Superfamily, and this protein was assigned TC\# 2.A.66.11.1.

A single protein (Q9KYG0; 239 aas; 2 TMSs) was found that showed low sequence similarity with an auxilary 
Table 3 Distant Sco transport proteins

\begin{tabular}{|c|c|c|c|c|}
\hline Assigned TC number & UniProt acc number & Size (number of aas) & Number of TMSs & Family assignment \\
\hline 2.A.1.21.18 & Q9KXM8 & 463 & 12 & MFS Superfamily \\
\hline 2.A.1.21.19 & Q9KYD4 & 411 & 12 & MFS Superfamily \\
\hline 2.A.4.8.1 & Q9X897 & 234 & 6 & CDF Family \\
\hline 2.A.7.3.43 & 086513 & 334 & 9 & DMT Superfamily \\
\hline 2.A.16.4.6 & Q9KY69 & 338 & 10 & TDT Family \\
\hline 2.A.66.11.1 & Q9RJJ1 & 429 & 12 & MOP Superfamily \\
\hline 2.A.85.10.1 & Q9K4J6 & 752 & 12 & ArAE Family \\
\hline 2.A.85.10.2 & Q9AJZ2 & 753 & 9 & ArAE Family \\
\hline 8.A.3.4.1 & Q9KYG0 & 239 & 2 & MPA1-C Family \\
\hline 9.A.31.1.2 & Q9XA27 & 436 & 10 & SdpAB Family \\
\hline 9.B.36.1.2 & Q9AK72 & 226 & 6 & Hde Family \\
\hline 9.B.74.4.1 & Q9K3K9 & 357 & 6 & PIP Family \\
\hline 9.B.140.1.1 & Q9K4J8 & 280 & 6 & DUF1206 Family \\
\hline
\end{tabular}

Proteins were retrieved with GBLAST e-values between 0.1 and 0.001 , individually verified and assigned TC numbers as indicated.

transport protein found within TC category 8. It belongs to the Membrane-Periplasmic Auxilary-1 (MPA1) Protein with Cytoplasmic (C) Domain (MPA1-C or MPA1+ C) Family of complex carbohydrate exporters [30,31]. Proteins of this family function in conjunction with members of the Polysaccharide Transport (PST) Family (TC\# 2.A.66.2) within the MOP Superfamily. It is not known if this auxiliary protein functions together with the MOP Superfamily homologue, 2.A.66.11.1. However, it was encoded by a gene that is adjacent to a glycosyl transferase and a polysaccharide deacetylase, suggesting a role in polysaccharide export. Q9KYG0 was assigned TC\# 8.A.3.4.1.

Five additional proteins were identified that are homologues of proteins currently listed in TC Class 9 (putative transporters of unknown mechanism of action). The first of these, a YvaB homologue (Q9XA27; assigned TC\# 9.A.31.1.2; 10 TMSs and 436 aas), is a distantly related member of the SdpC Peptide Antibiotic-like Killing Factor exporter (SdpAB) Family [32]. Members of this family had been previously identified only in species closely related to bacilli. Although an SdpC homologue was not identified in $S$. coelicolor, homologues were identified in other Streptomyces species.

The second Class 9 protein identified in Sco was a 6 TMS homologue (Q9AK72; 6 TMSs; 226 aas), a member of the Acid Resistance Membrane Protein (HdeD) Family. It was assigned TC\# 9.B.36.1.2, but no functional assignment was possible. The third Class 9 protein (Q9K3K9; 357 aas; 6 TMSs) was assigned TC\# 9.B.74.4.1. It belongs to the Phage Infection Protein (PIP) Family. Homologues include putative transport proteins of the ABC-2 Superfamily. The fourth protein (Q9K4J8; 280 aas; 6 TMSs) was assigned TC \# 9.B.140.1.1, a member of a novel TC family. This protein belongs to the DUF1206 Family. Finally, the fifth Class 9 protein (Q9X9U1; 513aas; 6 TMSs) was assigned TC\# 9.B.141.1.1 and belongs to the YibE/F Family.

\section{Myxococcus xanthus Transporters}

Additional file 3: Table S3 and Figure 4 present an overall summary of the classes and subclasses of transporters found in Myxococcus xanthus (Mxa) according to TC number. We identified 355 integral membrane transport proteins encoded in the Mxa genome. The entire genome is 9.14 million base pairs and encodes 7,316 proteins. Thus, $4.8 \%$ of the proteins encoded within the genome of Mxa are recognized transmembrane transport proteins. This value does not include transport accessory proteins such as cytoplasmic ATPases and extracytoplasmic receptors.

\section{Types of transporters in Mxa}

Mxa encodes all of the major types of transport proteins represented in TCDB (see Table 4). 21 (5.9\%) of these proteins are simple channels, $153(43.1 \%)$ are secondary carriers, $146(41.1 \%)$ are primary active transport proteins, $7(2 \%)$ are likely to be group translocators, $10(2.8 \%)$ are transmembrane electron flow carriers, 8 (2.3\%) are auxiliary transport proteins, and $10(2.8 \%)$ are of unknown mechanism of action. It therefore appears that in Mxa, similar to Sco, primary and secondary active transporters are of about equal importance, while other defined types of transporters are of much lesser importance.

Of the channel proteins, almost all are alpha-type channels (Subclass 1.A). A few outer membrane porins (Subclass 1.B) were identified, but these were not examined more closely because of the recent extensive studies of Bhat et al. [33]. No potential channel-forming toxins 


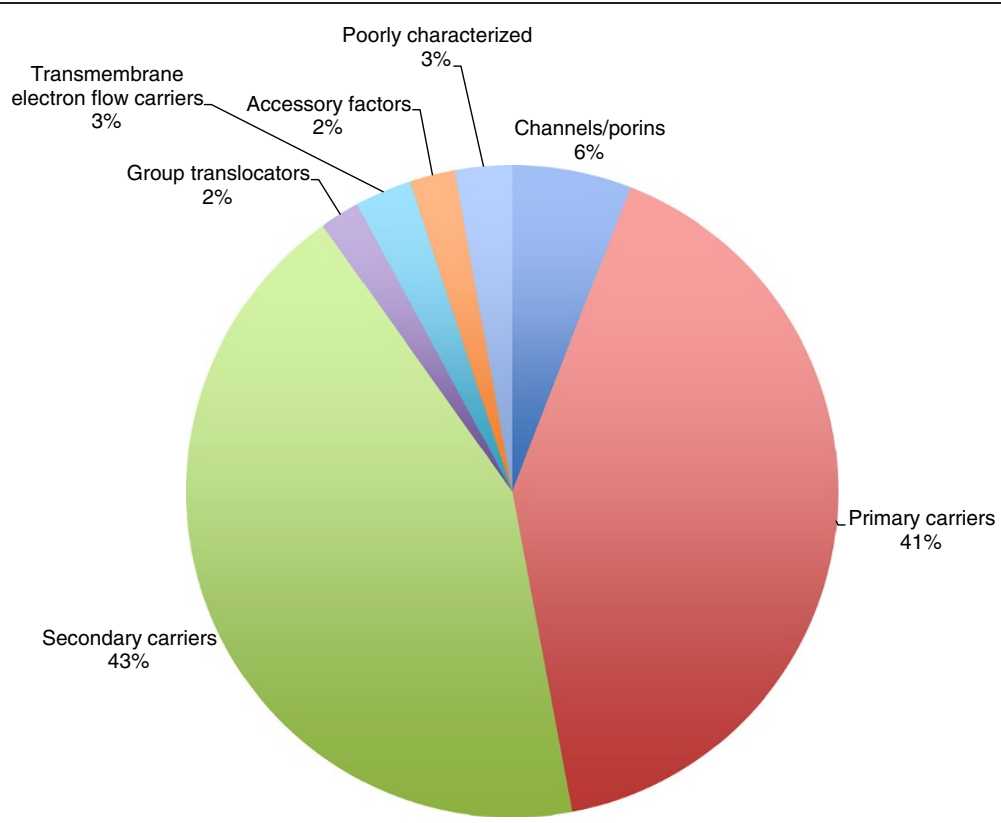

Figure 4 Myxococcus xanthus transporter type percentages. Transporter type percentages in Myxococcus xanthus, based on the Transporter Classification (TC) system.

(Subclass 1.C) were detected. The secondary carriers include mostly symporters (importers) and antiporters (exporters), while almost all primary active transporters are ATP-dependent (Subclass 3.A). However, a smaller percentage may be oxidoreduction driven (Subclass 3.D) or decarboxylation driven (Subclass 3.B). Among the seven group translocation proteins, two belong to the phosphotransferase system (Subclass 4.A), while five may be acyl CoA ligase-coupled transport systems (Subclass 4.C). Of the ten proteins possibly functioning as transmembrane electron flow carriers, all ten are likely to carry an electron pair (Subclass 5.A). None is likely to be a single electron carrier (Subclass 5.B). Eight auxiliary transport proteins (Subclass 8.A) and ten recognized transporters of unknown mechanism of action (Subclass 9.A) were also identified.

Table 4 Numbers of Mxa transport proteins according to TC class and subclass

\begin{tabular}{|c|c|c|c|c|c|}
\hline $\begin{array}{c}\mathrm{TC} \\
\text { class }^{\mathrm{a}}\end{array}$ & Class description & $\begin{array}{c}\text { No. of } \\
\text { proteins }\end{array}$ & $\begin{array}{c}\text { TC } \\
\text { subclass }\end{array}$ & Subclass description & $\begin{array}{c}\text { No. of } \\
\text { proteins }\end{array}$ \\
\hline \multirow[t]{2}{*}{1} & Channel/Pore & 21 & $1 . A$ & a-type channel & 18 \\
\hline & & & $1 . \mathrm{B}$ & $\beta$-type porin & 3 \\
\hline 2 & Secondary carrier & 153 & 2.A & Porter (uniporter, symporter, antiporter) & 153 \\
\hline \multirow[t]{3}{*}{3} & Primary active transporter & 146 & 3.A & P-P-bond hydrolysis-driven transporter & 124 \\
\hline & & & $3 . \mathrm{B}$ & Decarboxylation-driven transporter & 4 \\
\hline & & & 3.D & Oxidoreduction-driven transporter & 18 \\
\hline \multirow[t]{2}{*}{4} & Group translocator & 7 & 4.A & Phosphotransfer-driven group translocator & 2 \\
\hline & & & 4.C & Acyl CoA ligase-coupled transporter & 5 \\
\hline 5 & $\begin{array}{l}\text { Transmembrane electron } \\
\text { carrier }\end{array}$ & 10 & 5.A & Transmembrane 2-electron transfer carrier & 10 \\
\hline 8 & Auxiliary transport protein $^{\mathrm{b}}$ & 8 & $8 . \mathrm{A}$ & Auxiliary transport protein & 8 \\
\hline 9 & Poorly defined system & 10 & $9 . \mathrm{A}$ & $\begin{array}{c}\text { Recognized transporter of unknown biochemical } \\
\text { mechanism }\end{array}$ & 10 \\
\hline Total & & 355 & & & 355 \\
\hline
\end{tabular}

Detailed class and subclass descriptions can be found at www.tcdb.org.

${ }^{a}$ Transporter classes 6 and 7 have not been assigned in the TC system yet and therefore are not listed here.

${ }^{\mathrm{b}}$ Auxiliary proteins facilitate transport via established transport systems and therefore are not counted as a separate system. 


\section{Substrates transported by Mxa}

Table 5 and Figure 5 show numbers of transport proteins in Sco organized according to substrate types. Transporters that utilize inorganic molecules as substrates make up a large portion of all transport proteins found in Mxa. Cation-specific transporters $(23.7 \%-84$ total) are split evenly between primary and secondary carrier systems (36 and 38 proteins, respectively) with only six recognized channels. There are markedly fewer inorganic anion transporters (5.1\% - 18 total), including 6 primary carriers and 10 secondary carriers. In comparison, there are relatively few electron transport systems in Mxa.

Carbon compounds are transported by relatively few systems in Mxa. Sugars and polyols (2.3\% - eight total) are taken up by a combination of primary carriers (four proteins), secondary carriers (two proteins), and group transolcators (two proteins). A single secondary carrier is responsible for di- and tricarboxylate transport, while two secondary carriers are involved in organoanion transport. Aromatic compounds are transported by four primary carriers. As a predatory bacterium, the lack of a wide variety of transporters with carbon based substrates in Mxa can possibly be due to a greater reliance on amine-based derivatives for sustenance; Bretscher and Kaiser showed that many mono- and disaccharides were not among the minimal medium requirements for vegetative growth of Mxa colonies [34].

Amino acids and their derivatives are transported by a much greater variety of transporters. Amino acids and their conjugates $(5.6 \%-20$ total $)$ are transported primarily by secondary carriers (14 proteins), with approximately half as many primary carriers (six proteins). A single channel functions in amine, amide, polyamine and organocation transport. Peptides $(5.9 \%-21$ total) are taken up or expelled via 12 primary carriers and nine secondary carriers. Thus, relative to transporters specific for saccharide-based substrates, the high number of transporters for amine-based substrates indicates that Mxa uses amino acids and their derivatives as its main sources of carbon, an observation that has also been suggested in other studies [12].

Vitamins and other cofactor precursors $(2.0 \%$ - seven total) are taken up more by primary active transporters than by secondary carriers. Two primary carriers and a single secondary carrier may be involved in siderophore/ siderophore-iron complex transport. Nucleosides/nucleotides are transported by one channel, one secondary carrier, and two primary active transporters.

Transporters for drugs, toxins and other hydrophobic substances are primarily secondary carriers. Systems capable of exporting multiple drugs $(9.6 \%-34$ total) are almost exclusively secondary carriers (32 proteins). No Mxa transporter specific for pigments was identified, but transporters specific for toxins and other hydrophobic substances proved also to be secondary carriers.

Macromolecular exporters transporting complex carbohydrates, proteins and lipids were identified. Of the carbohydrate transporters, two are primary active transporters and nine are secondary carriers. Almost all protein exporters are primary carriers. A total of 17 systems (4.8\%) were found to transport lipids, mostly by primary carriers, although a few secondary carriers and potential group translocators were also identified. The expanded diversity of protein transport systems is probably a reflection of the tracking and microbial killing mechanisms used by Mxa, which secretes hydrolytic enzymes and secondary metabolites with antimicrobial activities [35].

\section{Topological analyses of Mxa transporters}

We analyzed the predicted topologies of all retrieved Mxa transport proteins (Figure 6a). For the most part, proteins with even numbers of TMSs outnumber proteins with odd numbers of TMSs, with notable discrepancies in channel proteins (Subclasses 1.A and 1.B) and active transporters. Single TMS primary active transport proteins are mostly $A B C$ extracytoplasmic solute receptors with one N-terminal signal TMS, while the high number of 3 TMS proteins in 1.B is due to eight members of the Mot-Exb Superfamily, involved in motility as well as outer membrane transport. Among transporters with even numbered TMSs, 6 and 12 TMS proteins are most numerous, encompassing members of the ABC Superfamily and the MFS, respectively.

\section{Identification of distant transport proteins in Mxa}

To identify distant transport protein homologues in Mxa, the same procedure was used as for Sco. In Mxa, over 130 sequences were retrieved with values between 0.001 and 0.1 . Similarly to Sco, most proved to be false positives with only 8 proving to be true homologues of existing TC entries; all 8 have been entered into TCDB (see Table 6).

A single protein (Q1D5P4; 432 aas; 14 TMSs) proved to be a member of the Monovalent Cation:Proton Antiporter-2 (CPA2) Family, and it was assigned TC\# 2. A.37.6.1 in a novel subfamily. It could be a $\mathrm{K}^{+}: \mathrm{H}^{+}$or $\mathrm{Na}^{+}$: $\mathrm{H}^{+}$antiporter. A second protein (Q1DCP3; 290 aas; 10 TMSs) was shown to be a member of the Drug/Metabolite Transporter (DMT) Superfamily, distantly related to members of the Drug Metabolite Exporter (DME) Family. It was assigned TC \# 2.A.7.31.1, also in a novel subfamily. A third protein (Q1D7B4; 506 aas; 14 TMSs) was assigned TC\# 2.A.66.12.1 as a member of the Multidrug/ Oligosaccharidyl-lipid/Polysaccharide (MOP) Flippase Superfamily. It belongs to a family within this superfamily for which no functional data are available. A fourth 
Table 5 Counts of Mxa transport proteins according to substrate type

Substrate No. of proteins of indicated type acting on substrate type

\begin{tabular}{cccccccc}
\hline $\begin{array}{c}\text { Channels/ } \\
\text { Pores }\end{array}$ & $\begin{array}{c}\text { Primary } \\
\text { carriers }\end{array}$ & $\begin{array}{c}\text { Secondary } \\
\text { carriers }\end{array}$ & $\begin{array}{c}\text { Group } \\
\text { translocators }\end{array}$ & $\begin{array}{c}\text { Transmembrane } \\
\text { electron flow } \\
\text { carriers }\end{array}$ & $\begin{array}{c}\text { Auxiliary } \\
\text { proteins }\end{array}$ & $\begin{array}{c}\text { (Putative) } \\
\text { Poorly } \\
\text { characterized }\end{array}$ & $\begin{array}{c}\text { Total no. } \\
\text { of systems }\end{array}$ \\
\hline
\end{tabular}

I. Inorganic molecules

$\begin{array}{lcccccc}\text { A. Nonselective } & 3 & & & & 3 \\ \text { B. } & \text { Cations } & 6 & 36 & 38 & 1 & 3 \\ \text { C. } & \text { Anions } & & 6 & 10 & 2 & 18 \\ \text { D. } & \text { Electrons } & & 4 & & 3 & 7\end{array}$

\section{Carbon sources}

A. Sugars \& polyols

B. Monocarboxylates

C. Di- \& tricarboxylates

D. Organoanions (noncarboxylic)

E. Aromatic Compounds

III. Amino acids \& their derivatives
A. Amino acids \& conjugates
B. Amines, amides, polyamines, \& organocations
C. Peptides
IV. Vitamins, cofactors \& cofactor precursors
A. Vitamins \& vitamin or cofactor precursors
B. Enzyme \& redox cofactors
C. Siderophores; siderophore-Fe complexes

D. Nucleosides/nucleotides

\section{Drugs, dyes, sterols \&} toxins

$\begin{array}{ccc}\text { A. } & \text { Multiple drugs } & 1 \\ \text { B. } & \text { Specific drugs } & 11 \\ \text { C. } & \text { Pigments } & \\ \text { D. } & \begin{array}{c}\text { Other hydrophobic } \\ \text { substances }\end{array} \\ \text { E. } & \text { Toxins } & 6 \\ \text { F. } & \text { Virulence factors } & 4\end{array}$

VI. Macromolecules
A. Carbohydrates
B. Proteins
C. Lipids

VII. Nucleic acids

A. Nucleic acids

$\begin{array}{ll}2 & 9 \\ 19 & 1 \\ 9 & 3\end{array}$


Table 5 Counts of Mxa transport proteins according to substrate type (Continued)

\begin{tabular}{|c|c|c|c|c|c|c|c|c|c|}
\hline & II. Water & & & & & & & & \\
\hline \multirow[t]{2}{*}{ A. } & Water & 1 & & & & & & & 1 \\
\hline & Unknown & & & & & & & & \\
\hline \multirow[t]{2}{*}{ A. } & Unknown & & 17 & 20 & & 4 & & 4 & 45 \\
\hline & Total & 21 & 146 & 153 & 7 & 10 & 8 & 10 & 355 \\
\hline
\end{tabular}

Substrate categories include: (I) inorganic molecules; (II) carbon sources; (III) amino acids \& their derivatives; (IV) vitamins, cofactors \& cofactor precursors; (V) drugs, dyes, sterols \& toxins; (VI) macromolecules; (VII) nucleic acids; and (VIII) unknown.

protein (Q1DA07; 731 aas; 13 TMSs) belongs to the Major Facilitator Superfamily (MFS) and was assigned TC\# 2.A.1.15.16. The gene of this protein is adjacent to a putative S-adenosyl methionine (SAM)-dependent methyltransferase whose homologues include puromycin methyltransferases. The substrate of this protein is potentially a drug that undergoes modification by methylation for detoxification purposes.

Two proteins proved to be members of the ABC-2 Superfamily within the ATP-binding Cassette (ABC) Functional Superfamily [28]. One protein (Q1D520; 1200 aas; 13 TMSs) was assigned to a new ABC family with TC\# 3.A.1.145.1. Notably, this exporter proved to be a fusion between an N-terminal ABC-2 domain with 13 putative TMSs and a hydrophilic C-terminal zinc dependent amino peptidase domain (Peptidase M1 Family), suggesting that the transporter domain could be involved in the export of an amino acid, amino acid derivative, or product of amino acid metabolism. In addition, Q1D520 resembles (35.4\% identity and 54.6\% similarity with 4 gaps) 3.A.1.145.3, another ABC-2 export permease fusion protein annotated as being involved in multi-copper enzyme maturation. The other ABC protein (Q1D0V1; 266 aas; 6 TMSs) was assigned TC\# 3.A.1.144.3 and is functionally uncharacterized.
Two proteins were shown to be homologous to proteins in TC Category 9. The first protein (Q1CXZ2; 211 aas; 3 TMSs) was found to be a member of the Cannabalism Toxin SdpC (SdpC) Family and was assigned TC\# 9.B.139.2.1. The second protein (Q1D006; 242 aas; 7 TMSs) was assigned TC\# 9.B.104.6.1. It belongs to the Rhomboid Protease Family and shows sequence similarity to members of the MFS; this result provides preliminary evidence that the MFS and Rhomboid Protease Family may in fact be homologous and warrants future investigation.

\section{Comparison of Streptomyces coelicolor (Sco) with Myxococcus xanthus (Mxa)}

As noted above, the genomes of Sco and Mxa are nearly the same size ( $\sim 9 \mathrm{Mbps})$, but the numbers of reported proteins in the proteomes differ substantially (8153 versus 7316 proteins, respectively; about $10 \%$ less for Mxa) $[11,12,36]$; See Discussion for an explanation. Moreover, using the same setting (cut-off of 0.001 representing values giving fairly reliably related homologues) for G-BLAST searches of the two genomes, the numbers of integral membrane transport protein hits were dramatically different (658 for Sco versus 355 for Mxa). It is possible that some of these differences reflect the criteria used for protein identification used by the annotators of the
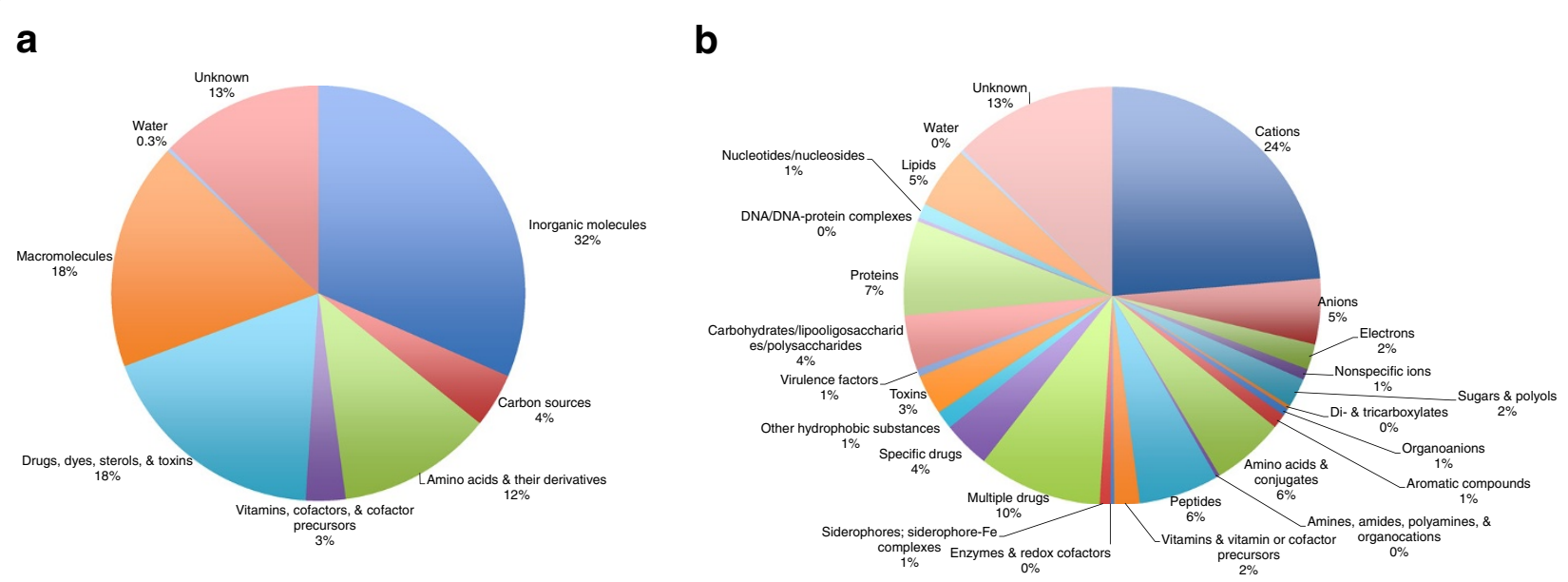

Figure 5 Myxococcus xanthus transported substrate types. Types of substrates transported in Myxococcus xanthus by class a) and subclass b). 


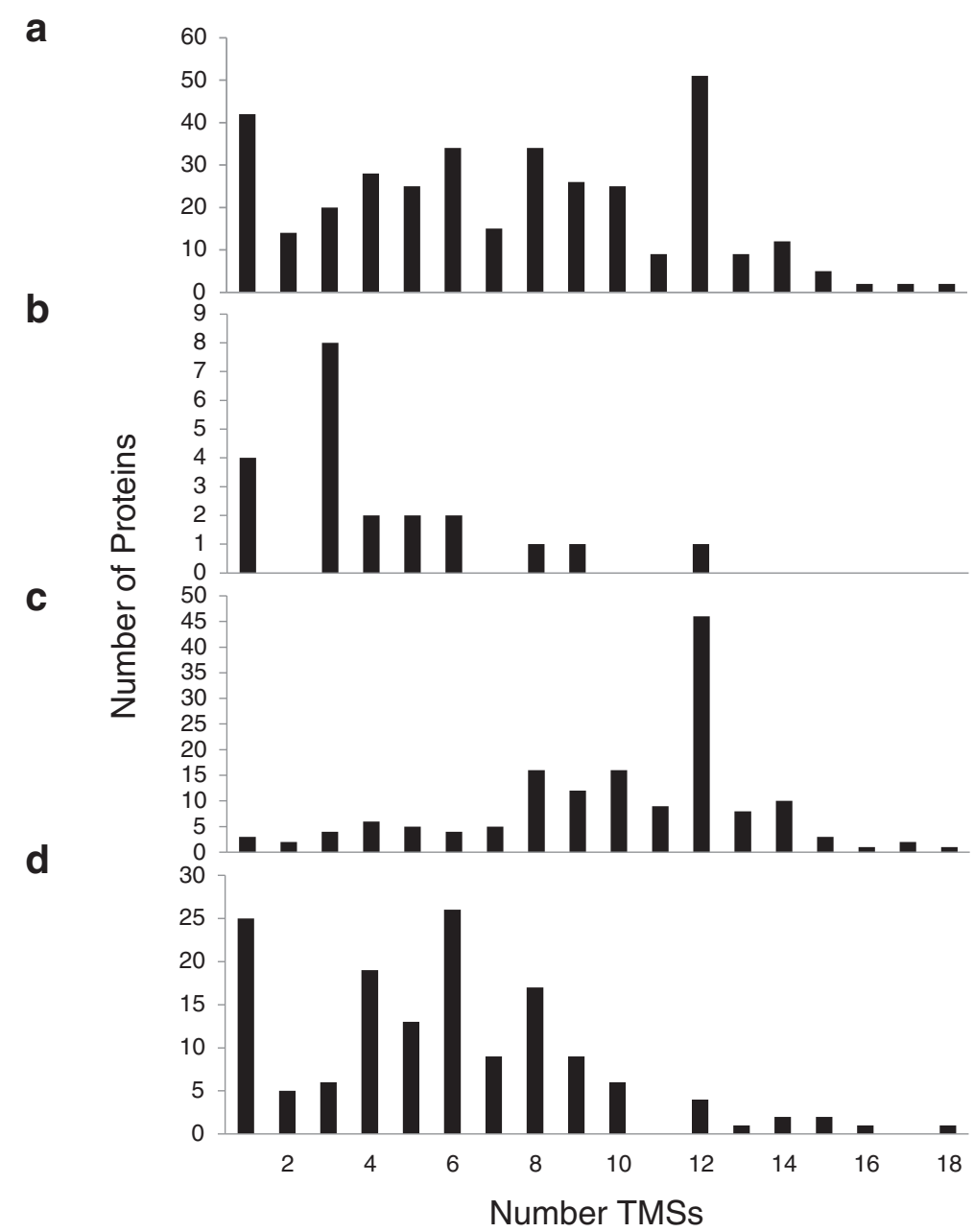

Figure 6 Myxococcus xanthus transport protein topologies. Transport protein topologies for all a) proteins, b) channels, c) secondary carriers, and d) primary active transporters in Myxococcus xanthus.

genome sequences of these two organisms. However, as noted below, these differences, particularly with respect to the numbers of transporters reported in Tables 1 and 4, are likely to reflect fundamental differences between the two organisms. It is also possible, although unlikely, that these differences, in part, represent greater sequence divergence of Mxa transporters compared to Sco transporters relative to the existing proteins in TCDB at the time when these analyses were conducted. As a result, we could have missed transporters too divergent in sequence to be detected with

Table 6 Distant Mxa transport proteins

\begin{tabular}{|c|c|c|c|c|}
\hline Assigned TC \# & UniProt acc \# & Size (\# aas) & \# TMSs & Family assignment \\
\hline 2.A.1.15.16 & Q1DA07 & 731 & 13 & MFS Superfamily \\
\hline 2.A.7.31.1 & Q1DCP3 & 290 & 10 & DMT Superfamily \\
\hline 2.A.37.6.1 & Q1D5P4 & 432 & 14 & CPA2 Family \\
\hline 2.A.66.12.1 & Q1D7B4 & 506 & 14 & MOP Superfamily \\
\hline 3.A.1.144.3 & Q1D0V1 & 266 & 6 & ABC Superfamily \\
\hline 3.A.1.145.1 & Q1D520 & 1200 & 13 & ABC Superfamily \\
\hline 9.B.139.2.1 & Q1CXZ2 & 211 & 3 & SdpC Family \\
\hline 9.B.104.6.1 & Q1D006 & 242 & 7 & Rhomboid Family \\
\hline
\end{tabular}

Proteins were retrieved with GBLAST e-values between 0.1 and 0.001 , individually verified and assigned TC numbers as indicated. 
the selected cut-off value. Because analyses of distant transport homologues of Sco and Mxa were performed, this possibility seems unlikely. Instead, Sco appears to have greatly amplified the numbers of certain types of transporters. The following comparisons and descriptions are pertinent to homologues obtained with scores smaller than (better than) the 0.001 threshold.

\section{Channel proteins}

The largest superfamily of channel proteins found in nature is the Voltage-gated Ion Channel (VIC) Superfamily (TC\# 1.A.1-5 and 10) [37,38]. While Sco has six VIC family (1.A.1) members, Mxa has only one, and neither organism shows representation in the other families of the VIC Superfamily see superfamily hyperlink in TCDB; [39].

All of the hits in both organisms gave values sufficient to establish homology, but no two VIC family homologues in these two dissimilar organisms proved most similar to the same TC entry. Thus, in Sco, one protein most resembles the well-characterized 2 TMS KcsA $\mathrm{K}^{+}$channel of $S$. lividans [40], but no such homologue was identified in Mxa. Instead, the one VIC family member in Mxa is a 6 TMS $\mathrm{K}^{+}$channel resembling bacterial 6 TMS homologues (TC 1.A.1.24). Other VIC family members in Sco include 2 and 4 TMS VIC family homologues, sometimes with extra C-terminal TrkA-N Rossman NAD-binding domains that presumably function in regulation of channel activity. These novel proteins have been entered into TCDB.

Both Sco and Mxa have two MIP family aquaporins/ glycerol facilitators [41]. These four proteins hit different TC entries with good scores $\left(\leq \mathrm{e}^{-34}\right)$, demonstrating that they are indeed members of the MIP family. They probably allow the passive flow of water and small neutral molecules such as glycerol across the bacterial plasma membranes. Sco also has a simple anion channel of the CLC Family (1.A.11) that is lacking in Mxa.

Mechanosensitive channels include MscL and MscS proteins, both involved in osmotic adaptation, acting as emergency release valves [42]. Only Sco has an MscL channel (1.A.22), but both organisms have four MscS proteins, some of which are similar between the two organisms. For example, Sco Q9S2Y1 and Mxa Q1D0J8 are $39 \%$ identical throughout most of their lengths and have therefore been assigned TC\#s 1.A.23.7.1 and 1. A.23.7.2, respectively. Moreover, both Sco Q86576 and Sco Q9L1X9 show >33\% identity throughout major portions of their sequences with Mxa Q1DEP9.

Mxa has eight proteins belonging to the multicomponent Mot-Exb Family (1.A.30) of $\mathrm{H}^{+}$or $\mathrm{Na}^{+}$channel chemiosmotic energizers used for motility and/or outer membrane transport. Sco, being a Gram-positive organism, lacks these homologues. Since it lacks flagellar motility, Mxa lacks MotA/MotB as expected, but it has several TolQ/TolR energizers for transport across the outer membrane [43]. In most cases, both TolQ and TolR were identified, although only TolQ homologues are listed in Table 2 . These protein pairs have been entered into TCDB under TC\#s 1.A.30.2.3 - 1.A.30.2.7.

Two other systems specific to Gram-negative bacteria but lacking in Gram-positive bacteria are the Outer Membrane Protein Insertion Porin (Bam or OmpIP) Family (1.B.33) [44,45] and the Outer Membrane Lipopolysaccharide Export Porin (LPS-EP) Family (1.B.42) [46,47]. As expected, constituents of these two systems were identified in Mxa, but not Sco. Although only some of these constituents are listed in Table 4, homologues of the E. coli constituents were identified, sometimes in multiple copies. Outer membrane porins of Mxa have been examined by Bhat et al., [33] and were therefore not considered further here. Several of these sequence divergent proteins have been included in TCDB.

\section{Secondary carriers (TC Sub-class 2.A) \\ The major facilitator superfamily (MFS)}

The largest superfamily of secondary carriers found in nature is the MFS [48,49]. Within the MFS (2.A.1), Sco has 114 recognizable homologues, while Mxa has only 32 . This huge difference accounts for a significant fraction of the total number of transporters Sco has in excess of those that Mxa has (82 of 203, or 41\%). Those proteins with low scores to preexisting entries in TCDB (E-values of $>\mathrm{e}^{-10}$ ) were entered into this database, thus allowing recognition of more distantly related family members in future studies.

A summary of MFS members in Sco and Mxa is presented in Table 7. Almost no sugar transporters of the MFS are found in either Sco or Mxa. Thus, while Sco has two members of the sugar porter (SP) family (2.A.1.1), Mxa has none, and sugar transporters of the OHS (2.A.1.5), FHS (2.A.1.7), NHS (2.A.1.10), SHS (2. A.1.12), PP (2.A.1.18), SET (2.A.1.20), and GPH (2.A.2) families are not represented in either organism. As will be demonstrated below, sugar transporters in Sco belong primarily to the $\mathrm{ABC}$ and PTS functional superfamilies.

Drug exporters are prevalent in both organisms. The DHA1 Family (2.A.1.2) has 12 members in Sco and nine in Mxa, the DHA2 Family (2.A.1.3) has 49 members in Sco and six in Mxa, and the DHA3 Family (2.A.1.21) has six and seven members in these two organisms, respectively. It is clear that Sco, but not Mxa, has greatly increased its numbers of DHA2 family members, although neither did for DHA1 or DHA3 family members. The order of representation is therefore DHA2 > DHA1> DHA3 in Sco, with huge representation of DHA2 members, but DHA1 > DHA3 > DHA2 in Mxa, with much lower representation overall. These systems presumably 
Table 7 MFS members in Sco and Mxa

\begin{tabular}{|c|c|c|c|c|}
\hline $\begin{array}{l}\text { TC } \\
\text { Number }\end{array}$ & Family name & Known substrate range & Sco & Mxa \\
\hline 2.A.1.1 & The Sugar Porter (SP) Family & sugar and sugar derivative (uniport; symport); urate (antiport) & 2 & \\
\hline 2.A.1.2 & $\begin{array}{l}\text { The Drug: } H^{+} \text {Antiporter-1 (12 Spanner) (DHA1) } \\
\text { Family }\end{array}$ & $\begin{array}{l}\text { drug, polyamine, neurotransmitter, sugar, nucleobase/side, } \\
\text { siderophore, lipid (antiport); vitamin (symport) }\end{array}$ & 12 & 9 \\
\hline 2.A.1.3 & $\begin{array}{l}\text { The Drug: } \mathrm{H}^{+} \text {Antiporter-2 (14 Spanner) (DHA2) } \\
\text { Family }\end{array}$ & $\begin{array}{l}\text { drug, boron, bile acid, parquot, fatty acid, siderophore, amino acid } \\
\text { (antiport); pyrimidine (symport) }\end{array}$ & 49 & 6 \\
\hline 2.A.1.4 & The Organophosphate:Pi Antiporter (OPA) Family & carbohydrate phosphate (antiport) & & 1 \\
\hline 2.A.1.6 & The Metabolite: $\mathrm{H}^{+}$Symporter (MHS) Family & organic acid/base, sugar acid (symport) & 6 & 1 \\
\hline 2.A.1.8 & The Nitrate/Nitrite Porter (NNP) family & nitrate/nitrite (symport/antiport) & 2 & 1 \\
\hline 2.A.1.11 & The Oxalate:Formate Antiporter (OFA) Family & oxalate/formate (antiport) & 3 & \\
\hline 2.A.1.14 & The Anion:Cation Symporter (ACS) Family & $\begin{array}{l}\text { organic and inorganic anion, peptide, vitamin, amino acid, nucleotide } \\
\text { (uniport; symport) }\end{array}$ & 3 & \\
\hline 2.A.1.15 & The Aromatic Acid: $\mathrm{H}^{+}$Symporter (AAHS) Family & aromatic acid, vitamin (symport) & 3 & 1 \\
\hline 2.A.1.17 & The Cyanate Porter (CP) Family & cyanate, glucose (symport) & 3 & \\
\hline 2.A.1.21 & $\begin{array}{l}\text { The Drug: } \mathrm{H}^{+} \text {Antiporter-3 (12 Spanner) (DHA3) } \\
\text { Family }\end{array}$ & drug, siderophore (antiport) & 6 & 7 \\
\hline 2.A.1.24 & The Unknown Major Facilitator-1 (UMF1) Family & unknown & 1 & 1 \\
\hline 2.A.1.25 & $\begin{array}{l}\text { The Peptide-Acetyl-Coenzyme A Transporter (PAT) } \\
\text { Family }\end{array}$ & peptide, glycopeptide, acyl-CoA (symport) & & 3 \\
\hline 2.A.1.30 & $\begin{array}{l}\text { The Putative Abietane Diterpenoid Transporter (ADT) } \\
\text { Family }\end{array}$ & diterpenoid (symport) & 4 & \\
\hline 2.A.1.34 & The Sensor Kinase-MFS Fusion (SK-MFS) Family & unknown & 1 & \\
\hline 2.A.1.35 & The Fosmidomycin Resistance (Fsr) Family & drug (antiport) & 1 & \\
\hline 2.A.1.36 & The Acriflavin-sensitivity (YnfM) Family & drug (symport) & 2 & 1 \\
\hline 2.A.1.40 & The Purine Transporter, AzgA (AzgA) Family & purine (symport) & 2 & \\
\hline 2.A.1.49 & The Endosomal Spinster (Spinster) Family & unknown & & 1 \\
\hline 2.A.1.54 & $\begin{array}{l}\text { The Unknown (Archaeal/Bacterial) Major Facilitator-9 } \\
\text { (UMF9) Family }\end{array}$ & unknown & 1 & \\
\hline 2.A.1.60 & The Rhizopine-related MocC (MocC) Family & rhizopine & 7 & 1 \\
\hline 2.A.1.67 & The Unidentified Major Facilitator-16 (UMF16) Family & unknown & 5 & \\
\hline 2.A.17 & $\begin{array}{l}\text { The Proton-dependent Oligopeptide Transporter } \\
\text { (POT) Family }\end{array}$ & peptide, histidine, nitrate (symport; occasionally antiport) & 1 & 2 \\
\hline
\end{tabular}

Representation of transporters belonging to known families within the Major Facilitator Superfamily (MFS) listed according to TC number with their substrate ranges and modes of active transport indicated.

reflect the abilities of Sco and Mxa to produce and export antimicrobial agents and to protect themselves against toxic substances produced by other soil microorganisms. However, we do not know why Sco amplified its membership in the DHA2 family but not the DHA1 or DHA3 family.

The MHS Family (2.A.1.6) includes members that transport a wide range of metabolites, particularly organic acids such as Krebs cycle intermediates. While Mxa has one such member, Sco has six. Other MFS families that may take up organic acids that are represented in Sco to a greater extent than in Mxa include the OFA (3;0), ACS $(3 ; 0)$, AAHS $(3 ; 1)$ and CP $(3 ; 0)$ Families. It therefore appears that Sco uses organic acids to a much greater extent than does Mxa.
Other interesting observations are: (1) Sco has four members of the poorly characterized ADT (Adietane) Family while Mxa has none; (2) Mxa has three peptide uptake systems of the AAT Family while Sco has none; (3) both organisms have nitrate:nitrite porters of the NNP Family; (4) both have members of the YnfM (acriflavin sensitivity) Family (of unknown physiological function); (5) Sco has seven members of the MocC (Rhizopine) Family while Mxa has only one, and (6) Sco has representation in the functionally uncharacterized UMF1 (one), UMF9 (one) and UMF16 (five members), while Mxa has representation (a single protein) only in the UMF1 family. Perhaps of greatest surprise is the fact that Mxa has a member of the AAA Family, members of which are usually restricted to obligatory intracellular parasites that 
utilize the cytoplasmic nucleotides of their hosts as energy sources [50]. The Mxa protein is a homologue $\left(\mathrm{e}^{-41}\right)$ of a characterized $\mathrm{NAD}^{+}$:ADP antiporter (2.A.12.4.1) [51]. Possibly, Mxa can take up nucleotides such as $\mathrm{NAD}^{+}$, ATP and ADP from the medium. Since it is a "micropredator" which lyses other bacteria, the presence of nucleotides in its growth medium would not be unexpected [52] (see Discussion). Another surprise was the discovery that Mxa and other bacteria have homologues of Spinster (Spns1 and 2), intracellular organellar sphingosine-1-phosphate or sphingolipid transporters involved in immune development, lymphocyte trafficking, and necrotic and antiphagic cell death in animals [53-56]. NCBI-BLAST searches revealed that many bacteria encode these homologues in their genomes. Two of these bacterial proteins have been entered into TCDB under TC\#s 2.A.1.49.7 and 8. It will be interesting to learn if the substrates of these prokaryotic transporters are the same as in eukaryotes. Sphingolipids represent a major outer membrane lipid class in some myxobacteria [57].

\section{The amino acid/polyamine/organocation (APC) superfamily}

Eleven families currently comprise the APC Superfamily (see TCDB), and most of them (seven) are concerned with the uptake of amino acids and their derivatives $[58,59]$. Sco has 32 APC superfamily members while Mxa has only six. Table 8 lists the numbers of representatives of these families in Sco and Mxa. The largest family within the APC Superfamily is the APC Family, and Sco has 17 such proteins while Mxa has only two.

The SSS Family of solute: $\mathrm{Na}^{+}$symporters, a constituent member of the APC Superfamily [59], transports a wide variety of solutes. Of the eight SSS family members in Sco, five probably transport short monocarboxylic acids (acetate, lactate, pyruvate, etc.), while three probably transport sugars. Of the four hits in Mxa, two may be monocarboxylate transporters while the other two are probably non-transporting signal transduction proteins with C-terminal sensor kinase domains. Only one of them is homologous to SSS transporters in its transmembrane domain.

\section{Heavy metal carriers}

Both Sco and Mxa have members (five and three members, respectively) of the heavy metal efflux Cation Diffusion Facilitator (CDF) Family 2.A.4; [60], but only Mxa has members (two) of the metal uptake Zinc-Iron Permease (ZIP) Family 2.A.5; [61]. Only Sco has a member of the Nramp Family of divalent cation transporters. These proteins exhibit varying specificities for heavy metals and are involved in metal ion homeostasis. Heavy metal transporters are also found in other families such as the RND Superfamily.

\section{The RND superfamily}

The RND Superfamily 2.A.6; [62,63] is well represented in both Sco and Mxa with 16 members in Sco and 20 in Mxa. Family 1 (Heavy Metal Efflux (HME)) is prevalent in Mxa with six members (see TCDB; 2.A.6.1.7-11 and 2.A.6.3.2), but absent in Sco. Based on induction properties, one may export $\mathrm{Zn}^{2+}$, two may export heavy metals (one of these is induced under starvation conditions), and three may export copper [64]. Similarly, the (largely Gramnegative bacterial) Hydrophobe/Amphiphile Efflux-1 (HAE1) Family (Family 2), usually considered to be concerned with drug export, is found in Mxa (four members) but not Sco. Surprisingly, the lipooligosaccharide Nodulation Factor Exporter (NFE) Family (Family 3) is represented in both organisms, but with six members in Mxa and only one in Sco. These proteins may transport substrates resembling rhizobial nodulation factor lipooligosaccharides, which are the substrates of the only characterized member of the NFE Family [65]. Such substrates are not known to be present in myxobacteria or actinobacteria. The reason for the presence of six

Table 8 APC family member representation in Sco and Mxa

\begin{tabular}{lll}
\hline TC \# & Family & Sco \\
\hline 2.A.3 & Amino Acid-Polyamine-Organocation (APC) Superfamily & 17 \\
2.A.15 & Betaine/Carnitine/Choline Transporter (BCCT) Family & 1 \\
2.A.18 & Amino Acid/Auxin Permease (AAAP) Family & 2 \\
2.A.21 & Solute:Sodium Symporter (SSS) Family & 8 \\
2.A.22 & Neurotransmitter:Sodium Symporter (NSS) Family & 1 \\
2.A.25 & Alanine or Glycine:Cation Symporter (AGCS) Family & 4 \\
2.A.30 & Cation-Chloride Cotransporter (CCC) Family & 5 \\
2.A.42 & Nucleobase:Cation Symporter-1 (NCS1) Family & 5 \\
\hline
\end{tabular}

Numbers of APC Superfamily proteins in Sco and Mxa are arranged by family. 
such homologues in Mxa is unexplained, but it suggests that this $\delta$-proteobacterium, other myxobacteria, and possible actinobacteria may similarly use extracellular lipooligosaccharides for purposes of communication.

Both organisms have a single member of the SecDF Family (RND Family 4) as expected for large genome bacteria. This protein pair facilitates protein secretion via the general secretory system (Sec translocase; 3.A.5), by a mechanism that involves ATP-independent pmf-driven substrate protein translocation where SecDF transports protons down their electrochemical gradient to drive protein export [66]. Also as expected, Sco, but not Mxa, has representation (14 members) of the largely Gram-positive bacterial HAE2 Family (RND Family 5) [63]. HAE2 family homologues function to export complex lipids to the outer actinobacterial membrane [67], although some of them may catalyze the export of antimicrobial agents (see TCDB). Finally, Mxa, but not Sco, has four members of the HAE3 Family (Family 7); functional data for members of this family are available for only one member which proved to be an exporter of hopanoids, fused pentacyclic ring cholesterol-like compounds [68].

\section{The drug/metabolite transporter (DMT) superfamily}

The DMT Superfamily 2.A.7; [69] is well represented with 17 members in Sco and 13 in Mxa. These proteins fall within several DMT families. Both organisms have members of the 4 TMS Small Multidrug Resistance (SMR) Family (Family 1), but only Mxa has a member of the functionally uncharacterized 5 TMS BAT Family (Family 2). Sco and Mxa have eight and five members, respectively, of the DME Family (Family 3) that may primarily export metabolites such as amino acids. Other families within this superfamily are primarily concerned with transport of activated sugars for glycolipid and polysaccharide synthesis, but they are not represented in either Mxa or Sco.

\section{Other secondary carriers}

Two members of the GntP Family (2.A.8) of uptake porters for gluconate and other organic acids are found in Sco but not Mxa, in agreement with a greater dependency of metabolism of the former on carbohydrates and organic acids. Sco also has single members of each of the CitMHS, LctP, BCCT and TDT families of carboxylate uptake transporters, all of which are lacking in Mxa. This observation also points to a greater dependency of Sco on organic acids as sources of nutrition.

While Sco has two YidC homologues, involved in integral membrane protein insertion in many bacteria [70], only one such homologue was found in Mxa. Interestingly, while E. coli has only one YidC, Bacillus subtilis has two, one for vegetative growth (OxaA2) and one for sporulation
(SpoIII) [71]. It is possible that Sco uses its two YidC homologues for these two distinct purposes, but Mxa, with a single homologue, evidently lacks such a need. It must use the same protein for integral membrane protein insertion during both vegetative growth and spore development.

Sco but not Mxa has a $\mathrm{Ca}^{2+}$ :Cation Antiporter (CaCA Family), while Mxa, but not Sco, has a P-type $\mathrm{Ca}^{2+}$-ATPase. These two organisms therefore use different mechanisms to extrude $\mathrm{Ca}^{2+}$ from the cell cytoplasm. These differences may be important since $\mathrm{Ca}^{2+}$ plays roles in development and antibiotic production in both organisms [72-75]. Sco also has two phosphate transporters of the Pit family although Mxa has only one.

Both organisms have two or three members of the $\mathrm{Na}^{+}$: $\mathrm{H}^{+}$Antiporter (NhaA) Family. Both also have multiple members of the functionally related Cation:Proton Antiporter (CPA1 and CPA2) Families (6 and 9 for Mxa and Sco, respectively). Both bacteria have five members of the CPA2 Family, but they have one and four members of the CPA1 family, respectively. Although members of these two families are within the same superfamily, they are only distantly related. The general reactions catalyzed by members of these families are similar, but most CPA1 family members transport $\mathrm{Na}^{+}$while many CPA2 family members transport $\mathrm{K}^{+}$(see TCDB). They are involved in $\mathrm{pH}$ and inorganic cation homeostasis [76]. A single multicomponent cation: $\mathrm{H}^{+}$antiporter of the CPA3 Family is present in both organisms.

Both organisms have a single ArsB arsenite exporter, but only Sco has two arsenite exporters of the Arsenical Resistance-3 (ACR3) Family. Mxa and Sco have 3 and 1 members of the DASS Family, respectively. Members of this family take up both inorganic and organic anions, depending on the system. Both organisms have three paralogues of the SulP Family, which exclusively transport inorganic anions such as sulfate and bicarbonate. They also have two or three members of the Dicarboxylate/Amino Acid:Cation $\left(\mathrm{Na}^{+}\right.$or $\left.\mathrm{H}^{+}\right)$Symporter (DAACS) and Bile Acid: $\mathrm{Na}^{+}$Symporter (BASS) families which exclusively transport organic anions including amino acids. The two nucleobase:cation symporter families, NCS1 and NCS2, are prevalent in Sco (8 members), but appear to be lacking in Mxa.

Both Sco and Mxa have TatA and TatC homologues, the essential constituents of the Sec-independent twin arginine translocase protein secretion system [77]. However, while Sco has a 3-component system with TatA, B and $C$, Mxa appears to have a 2-component system with just one TatA/B homologue [78]. Many prokaryotes have either 2 or 3 component systems, but the advantages of the greater complexity of the 3-component systems are not well understood, although distinct but overlapping functions for the E. coli TatA and TatB paralogues are recognized $[77,78]$. 
The MOP Superfamily of multidrug/oligosaccharidyl lipid/polysaccharide exporters [79] is present in both organisms with Mxa having 7 members and Sco having 3. In Sco, one is probably a multidrug resistance pump while the other two may catalyze export of lipidpeptidoglycan precursors to the periplasm for cell wall assembly, as suggested by Ruiz [80]. B. subtilis has four such homologues, one of which, $\mathrm{SpoVB}$, is required for spore cortex polymerization [81]. However, Fay and Dworkin [82] have conducted experiments indicating that a strain deleted for all four genes grows normally, causing some doubt about the proposed function in lipid peptidoglycan precursor export. Possibly these porters export these substrates, but the presence of functionally redundant transporters might provide the explanation for this apparent contradiction. This possibility is reinforced by the fact that members of the bacterial specific MPE Family (2.A.103), present in almost all bacteria, are known to serve this function [83]; C.C. Zhang \& M.H. Saier, unpublished results. Mxa only has one such homologue, but Sco has two. Sco could use these two paralogues during vegetative growth and spore formation, respectively, although direct evidence for this proposal is not available. Mxa has two putative polysaccharide exporters of the MOP Superfamily that could be involved in polysaccharide export for social motility, fruiting body formation, stress survival, and/or biofilm formation [84].

Peptide signaling is known to be essential for normal fruiting body development in Mxa [85]. This organism has five peptide uptake porters of the OPT Family that could function both in this capacity and in nutrition. Surprisingly, Sco lacks such systems. Because Sco also uses peptide signaling $[2,86]$, it must use alternative mechanisms of peptide communication. It is likely that it uses $\mathrm{ABC}$ porters and transmembrane sensor kinases for signaling since in Gram-positive bacteria, signaling peptides are usually present in very low (sub-nanomolar) concentrations $[2,87]$.

Several families of small molecule (especially amino acid) efflux pumps are found in these sporulating bacteria. Thus, both have single AEC, RhtB, LIV-E and ThrE exporters, although only Sco has a LysE family member. Both organisms have multiple representation in the ArAE and AI-2E families: 4 and 4 members for Sco; 2 and 7 members for Mxa. While the former systems export aromatic acids, the latter transport interspecies signaling molecules such as autoinducer- 2 as well as other metabolites [88].

Several other secondary carrier families are represented in Sco and Mxa. Each bacterium has a single member of the VUT/ECF, UBS1 and NAAT families, but only Sco has a member of the VIT and UIT1 families while only Mxa has a PSE family member. While these systems are all expected to catalyze uptake, their substrates are diverse and in several cases, uncertain (see TCDB). The TSUP family is well represented with 3 members in Sco and 6 in Mxa. Several of these systems probably take up sulfur-containing compounds [89]. Finally, the last of the secondary carrier families represented, the Bacterial Murein Precursor Exporter (MPE) Family [83], involved in cell wall biosynthesis, is present in both bacteria as expected. Mxa, however, has only one such member, while Sco has 4 . It can be proposed that these distinct paralogues function at different stages of development in different cell types.

\section{Primary active transporters $A B C$ porters}

$A B C$ transporters consist of one or two multispanning integral membrane protein(s) (homo- or heterodimers), one or two cytoplasmic ATPase(s) (also homo- or heterodimers), and for most uptake (but not efflux) systems, one or more extracytoplasmic receptor(s), each with a single $\mathrm{N}$-terminal signal sequence. An examination of the integral membrane constituents of $\mathrm{ABC}$ transporters revealed that Sco has nearly three times as many $A B C$ membrane proteins as does Mxa (202 versus 72). This difference, as well as the nearly four-fold greater number of MFS carriers in Sco, provides the majority of differences in the numbers of membrane transport proteins found within these two organisms.

Table 9 lists the families, numbers per family, and probable substrates of the $\mathrm{ABC}$ uptake proteins found in these two organisms. $\mathrm{ABC}$ porters include 3 independently evolving protein types, $\mathrm{ABC} 1, \mathrm{ABC} 2$ and $\mathrm{ABC} 3$, and all three types are represented in both Sco and Mxa [28]. The most striking difference between Sco and Mxa is the large number of sugar porters in Sco (85) as compared with Mxa (6). However, Sco has 12 amino acid and 17 peptide $\mathrm{ABC}$ transport proteins while Mxa has only 4 and 3, respectively. It seems that while Mxa primarily uses secondary carriers of the OPT family for peptide uptake, Sco primarily uses transporters of the ABC superfamily.

These two organisms have similar low numbers of systems for inorganic anions, sulfate, phosphate, molybdate and phosphonates, but neither has an $\mathrm{ABC}$ nitrate/ nitrite uptake system. Instead, they both have MFS-type nitrate/nitrite transporters (see above). Sco has about 4 times as many $\mathrm{ABC}$ amine transport proteins as does Mxa. These two organisms have similar numbers of $\mathrm{ABC}$ iron uptake proteins (11 and 8, respectively). ABC uptake systems for inorganic cations are rare in both bacteria. Vitamin transporters are also scarce.

ABC-type export systems are less numerous than uptake systems in both organisms. However, some families are well represented in one or the other organism. Both have at least one putative LPS precursor 
Table 9 ABC uptake porters in Sco and Mxa

\begin{tabular}{|c|c|c|c|c|}
\hline \multicolumn{3}{|c|}{ ABC Family } & \multirow{2}{*}{$\begin{array}{l}\text { Sco } \\
75\end{array}$} & \multirow{2}{*}{$\frac{\text { Mxa }}{4}$} \\
\hline 1 & Carbohydrate Uptake Transporter-1 (CUT1) Family & Carbohydrates & & \\
\hline 2 & Carbohydrate Uptake Transporter-2 (CUT2) Family & Carbohydrates & 10 & 2 \\
\hline 3 & Polar Amino Acid Uptake Transporter (PAAT) Family & Polar amino acids & 5 & 1 \\
\hline 4 & Hydrophobic Amino Acid Uptake Transporter (HAAT) Family & Non-polar amino acids & 6 & 2 \\
\hline 5 & Peptide/Opine/Nickel Uptake Transporter (PepT) Family & Peptides, oligosaccharides & 17 & 3 \\
\hline 6 & Sulfate/Tungstate Uptake Transporter (SulT) Family & Sulfate & 1 & 1 \\
\hline 7 & Phosphate Uptake Transporter (PhoT) Family & Phosphate & 3 & 2 \\
\hline 8 & Molybdate Uptake Transporter (MoIT) Family & Molybdate & 1 & 1 \\
\hline 10 & Ferric Iron Uptake Transporter (FeT) Family & Iron & & 2 \\
\hline 11 & Polyamine/Opine/Phosphonate Uptake Transporter (POPT) Family & Polyamines/opines/phosphonates & 3 & \\
\hline 12 & Quaternary Amine Uptake Transporter (QAT) Family & Quaternary/amines & 6 & 2 \\
\hline 14 & Iron Chelate Uptake Transporter (FeCT) Family & Iron chelates & 8 & 4 \\
\hline 15 & Manganese/Zinc/Iron Chelate Uptake Transporter (MZT) Family & $\mathrm{Mn}^{2+} / \mathrm{Zn}^{2+} / \mathrm{Fe}^{2+}$ chelates & 2 & 1 \\
\hline 17 & Taurine Uptake Transporter (TauT) Family & Taurine & 2 & 2 \\
\hline 18 & Cobalt Uptake Transporter (CoT) Family & Cobalt $\left(\mathrm{Co}^{2+}\right)$ & 2 & \\
\hline 20 & Brachyspira Iron Transporter (BIT) Family & Iron & 1 & \\
\hline 21 & Siderophore-Fe $\mathrm{F}^{3+}$ Uptake Transporter (SIUT) Family & Siderophore-iron & 2 & 2 \\
\hline 23 & Nickel/Cobalt Uptake Transporter (NiCoT) Family & Nickel; cobalt & 2 & \\
\hline 24 & Methionine Uptake Transporter (MUT) Family & Methionine & 1 & 1 \\
\hline 27 & Y-Hexachlorocyclohexane (HCH) Family & y-hexachlorohexane/cholesterol & 2 & 4 \\
\hline 32 & Cobalamin Precursor $\left(\mathrm{B}_{12}-\mathrm{P}\right)$ Family & Vitamin B12 precursors & 2 & \\
\hline
\end{tabular}

Numbers of integral membrane $A B C$ uptake proteins in Sco and Mxa arranged by family.

export system (Family 103), several lipid exporters (Family 106), and several lipoprotein exporters (Family 125) (Table 10). ABC-type drug exporters are prevalent but with striking differences between the two organisms. Sco has ten DrugE1 export proteins (Family 105) while Mxa has only one. Both have a single DrugE2 exporter (Family 117), but while Sco has only one DrugE3 export protein (Family 119), Mxa has six. Most strikingly, while Sco has only one macrolid export protein (Family 122), Mxa has 16. They both have MDR pumps belonging to other $\mathrm{ABC}$ export families, including eukaryotic-type systems. In Mxa, two of these belong to the MDR Family (Family 201), while in Sco, 1 belongs to the EPP Family (Family 204). Protein and peptide exporters can also be found, but no family predominates in either organism, and representation of one family in one of these bacteria does not correlate with representation in the other (Table 10). It seems clear that these two organisms have solved the problems of macromolecular and drug export using very different transport systems and mechanisms. This fact probably reflects the independent evolution of the two sporulating organisms' lifestyles, as well as the production and secretion of different types of molecules. Thus, in spite of their striking physiological similarities (see Discussion), Sco and Mxa have used very different types of transport systems to satisfy their metabolic and developmental needs.

\section{ATPases in Sco and Mxa}

Both Sco and Mxa have a single F-type ATPase as indicated by the 3 integral membrane constituents listed in Additional file 1: Table S1 and Additional file 2: Table S2. These enzymes function to interconvert chemiosmotic energy (the proton motive force, pmf) with chemical energy (ATP). They both also have an $\mathrm{H}^{+}$-translocating pyrophosphatase complex. P-type ATPases in general appear to function in mediating stress responses in prokaryotes, and their occurrence by family in numerous organismal types has been defined [90,91]. Sco has eight such enzymes while Mxa has seven. While only Mxa has a $\mathrm{Ca}^{2+}$-ATPase (Family 2) and only Sco has a heavy metal ATPase (Family 6), both have the three components of Kdp-type $\mathrm{K}^{+}$uptake ATPases as well as three distinct copper ATPases. Remaining P-type ATPases in these organisms are functionally uncharacterized. Sco has two members of Family 23 and one member of Family 25 while Mxa has one member each of Families 27 and 32. While Family 23 members are of the type 2 ATPases with 
Table 10 ABC export porters in Sco and Mxa

\begin{tabular}{|c|c|c|c|c|c|}
\hline TC \# & Family name & Known substrate range & ABC Type & Sco & Mxa \\
\hline 3.A.1.103 & Lipopolysaccharide Exporter (LPSE) & LPS & 2 & 2 & 1 \\
\hline 3.A.1.105 & Drug Exporter-1 (DrugE1) & Drugs & 2 & 10 & 1 \\
\hline 3.A.1.106 & Lipid Exporter (LipidE) & PL, LPS, Lipid A, Drugs, Peptides & 1 & 6 & 3 \\
\hline 3.A.1.107 & Putative Heme Exporter (HemeE) & Heme, Cytochrome c & 2 & & 1 \\
\hline 3.A.1.109 & Protein-1 Exporter (Prot1E) & Proteins & 1 & & 1 \\
\hline 3.A.1.110 & Protein-2 Exporter (Prot2E) & Proteins & 1 & & 1 \\
\hline 3.A.1.111 & Peptide-1 Exporter (Pep1E) & Bacteriocin, Peptides & 1 & 2 & 1 \\
\hline 3.A.1.112 & Peptide-2 Exporter (Pep2E) & Other Peptides & 1 & 1 & \\
\hline 3.A.1.115 & $\mathrm{Na}^{+}$Exporter (NatE) & Sodium & 2 & & 1 \\
\hline 3.A.1.117 & Drug Exporter-2 (DrugE2) & Drugs, Lipids, Dyes & 1 & 1 & \\
\hline 3.A.1.119 & Drug/Siderophore Exporter-3 (DrugE3) & Drugs, Siderophores & 1 & 6 & \\
\hline 3.A.1.122 & Macrolide Exporter (MacB) & Macrolides, Heme & 3 & 1 & 16 \\
\hline 3.A.1.123 & Peptide-4 Exporter (Pep4E) & Drugs, Peptides & 1 & 1 & \\
\hline 3.A.1.125 & Lipoprotein Translocase (LPT) & O.M. Lipoproteins & 3 & 7 & 3 \\
\hline 3.A.1.127 & AmfS Peptide Exporter (AmfS-E) & Peptides, Morphogens & 2 & 2 & \\
\hline 3.A.1.129 & CydDC Cysteine Exporter (CydDC-E) & Cysteine & 1 & 1 & \\
\hline 3.A.1.132 & Gliding Motility ABC Transporter (Gld) & Polysaccharides, Copper lons & 2 & & 2 \\
\hline 3.A.1.134 & Peptide-7 Exporter (Pep7E) & Peptides, Bacteriocins & 3 & 1 & \\
\hline 3.A.1.135 & Drug Exporter-4 (DrugE4) & Drugs & 1 & 2 & \\
\hline 3.A.1.140 & FtsX/FtsE Septation (FtsX/FtsE) & Septation & & 1 & 1 \\
\hline 3.A.1.141 & Ethyl Viologen Exporter (EVE) & Ethylviologen & & 2 & 2 \\
\hline 3.A.1.201 & Multidrug Resistance Exporter (MDR) & Drugs, Fatty Acids, Lipids & 1 & & 2 \\
\hline 3.A.1.204 & Eye Pigment Precursor Transporter (EPP) & Pigments, Drugs, Hemes & 2 & 1 & \\
\hline 3.A.1.210 & Heavy Metal Transporter (HMT) & Drugs, Metal Conjugates, Heme & 1 & 1 & 1 \\
\hline
\end{tabular}

Numbers of integral membrane $A B C$ export proteins in Sco and Mxa arranged by family.

10 TMSs, Families 25, 27 and 32 have the basic type 1 topology of 6 TMSs plus or minus one or two extra N-terminal TMSs [91]. One member of Family 27 has been shown to function in the insertion of copper into copper-dependent oxidases, such as cytochrome oxidase, but not in copper tolerance [92]. This is probably the function of the enzyme in Mxa. Since both organisms have complete cytochrome oxidase systems, it may be that Sco uses an alternative mechanism to insert copper during the biogenesis of this enzyme complex. Possibly, it uses one of its three copper ATPases.

\section{Protein secretion}

As expected, both organisms have the general secretory pathway for protein export (TC\# 3.A.5) as well as the Twin arginine targeting (Tat) protein secretion system (TC\# 2.A.64) and the DNA translocase (DNA-T). Sco, but not Mxa, appears to have a type IV protein/DNA secretion system (found in both Gram-negative and Gram-positive bacteria). However, only Mxa has components of type II (MTB) and type III protein secretion systems, both present in certain Gram-negative bacteria but lacking in Gram-positive bacteria [93,94].

\section{Group translocation via the phosphoenolpyruvate- dependent sugar-transporting phosphotransferase system (PTS)}

Both Sco and Mxa have proteins of the PTS. However, while Mxa has only one sugar transporting system of the mannose family, Sco has five systems, one probably specific for glucose and maltose, two specific for $\mathrm{N}$-acetyl glucosamine and related sugars, a fourth specific for fructose, and a fifth that may transport L-ascorbate [95-98]. A link between N-acetyl glucosamine metabolism and the control of development in Sco has been reported [99,100], possibly explaining why two such systems are present. Thus, in agreement with observations previously discussed in this article, Sco apparently relies more heavily on sugars for carbon and energy than does Mxa, and the published data implies that it uses availability of these sugars (or at least $\mathrm{N}$-acetyl glucosamine) to control development. 


\section{Oxidative metabolism}

Both organisms have homologues of the putative fatty acid transporters of the FAT Family, DsbD homologues for the transfer of electrons across the cytoplasmic membrane for periplasmic sulfhydryl oxidoreduction, members of the Prokaryotic Molybdopterin-containing Oxidoreductase (PMO) Family, and a succinate dehydrogenase. The striking similarities between the proton-pumping electron transfer complexes of the TC 3.D subclass are particularly noteworthy. Apparently, Sco and Mxa have quantitatively similar complements of electron transfer carriers of all types, the most striking parallels we have observed for these two organisms.

\section{Transporters of unknown mechanisms of action}

It is interesting that both Sco and Mxa have members of the TerC and HCC families although in different numbers. While Mxa has two of each, Sco has 5 TerC homologues and $9 \mathrm{HCC}$ proteins. Although one TerC protein has been implicated in tellurium resistance, functions of its many homologues are probably diverse. HCC homologues, some or all of which are likely to be $\mathrm{Mg}^{2+}$ transporters, consist of three domains, an N-terminal 4 TMS DUF21 domain, a central nucleotide-binding CBS domain, and a C-terminal $\mathrm{HlyC} / \mathrm{CorC}$ domain. Only proteins within this family that possess the DUF21 domain are likely to be divalent cation transporters. All of the homologues in Sco and Mxa have the DUF21 domain, suggesting that they serve this function. Why Sco would need nine such proteins is a mystery, as most bacteria have only one or two, or lack them altogether. It can be proposed that they function in the regulation of differentiation where $\mathrm{Mg}^{2+}$ may play crucial roles in regulating the many ATP-dependent kinases, including, but not limited to, the 44 ser/thr kinases (see Discussion).

\section{Observed differences in gene size and number}

We downloaded Sco A3(2) and Mxa DK 1622 from Ensembl Bacteria (http://bacteria.ensembl.org/index. html). In Sco, there were 8,154 sequences and in Mxa 7,331 . The average protein size was 326 in Sco and 379 in Mxa. The genome size of Sco is 8.7 million bps and of Mxa, 9.1 million bps. We used Glimmer 3 (microbial Genscan) [101] against Sco (NC_003888) and Mxa (CP000113) and found 8,213 gene predictions for Sco. The average length (nt) was 939. For Mxa, there were 7,656 gene predictions, with an average length (nt) of 1075. These data are consistent with the concept that Sco has more and smaller genes, than Mxa.

\section{Transporters of experimentally verified function in Sco and Mxa}

We have screened the published literature for articles that provide experimental information about transporters in Sco and Mxa. A summary of the findings are presented in Table 11 which gives the protein designations, the Sco or Mxan genome numbers and the references in column 1 , the UniProt accession numbers in column 2, the TC\#s of the transport systems in column 3 , and the probable functions plus additional information if available in column 4. Of these proteins, only one system (AreABCD) of Sco was not included in our initial G-blast screen. It was missed because these sequences were too distant to anything then in TCDB to give a score better than our cutoff value of 0.001 . The AreABCD export system has been assigned TC\# 3.A.1.146.1 and represents a new family within the ABC superfamily.

The systems listed in Table 11 will not be discussed individually as the information provided in the table is self-explanatory. However, some entries are worthy of elaboration. For example, MdrA (Sco4007, [104]), is a putative MFS multi-drug exporter, based on the specificity of the regulatory protein that controls expression of its structural gene.

Three systems (DasABC, AglEFG and MalEFG; TC\#s 3.A.1.1.33, 3.A.1.1.43 and 3.A.1.1.44) were each encoded within operons that encoded a receptor (R) and two membrane $(\mathrm{M})$ proteins but no cytoplasmic ATPase $(\mathrm{C})$. In the case of the DasABC system, the separately encoded MsiK (multiple sugar import-K) ATPase protein has been shown to serve as the energy-coupling constituent of the system [106]. We infer that the same is true for the AglEFG and MalEFG systems because: (1) each of these sets of proteins are encoded in an operon that lacks a cytoplasmic ATPase, and (2) all three systems belong to the same TC family (CUT1; TC\#3. A.1.1) in which interchangeability of ATPases has been documented [106], and (3) an msiK null mutant has been shown to be unable to utilize several disaccharides including maltose [106].

Two ABC ferric iron-hydroxamate uptake porters of Sco have been characterized [113]. The CchCDEF system has been assigned TC\# 3.A.1.14.13 while the DesABC system has been assigned TC\# 3.A.1.14.12. Additionally, a putative $\mathrm{ABC}$ receptor, DesE, has been characterized, but its cognate transport proteins have not been identified [113]. Because the complete transport system was not recognized, this receptor was not entered into $\mathrm{TCDB}$, and because it gave a poor score with its closest homologue, it was not recognized by G-BLAST. We have previously shown that the three constituents (receptor protein, R; membrane protein, $\mathrm{M}$; and cytoplasmic ATPase, C) of ABC uptake porters coevolved almost without exception, therefore forming analogous phylogenetic trees [124]. However, while the genes encoding a complete $\mathrm{ABC}$ porter often cluster together, the receptor and/or ATPase may cluster separately. Based on these facts, we attempted to identify the most probable set of $\mathrm{ABC}$ proteins that function with DesE. 
Table 11 Functionally characterized Sco and Mxa proteins

\begin{tabular}{|c|c|c|c|}
\hline $\begin{array}{l}\text { Protein designation; Sco\# or Mxan\#, } \\
\text { and reference }\end{array}$ & $\begin{array}{l}\text { UniProt } \\
\text { Acc\# }\end{array}$ & TC\# & Probable or established function \\
\hline \multicolumn{4}{|c|}{ S. coelicolor } \\
\hline MscL; Sco3190 [102] & Q9KY5 & 1.A.22.1.10 & $\begin{array}{l}\text { MscL, osmotic adaptation channel that influences sporulation and secondary } \\
\text { metabolite production. }\end{array}$ \\
\hline GlcP1/2; Sco7153; Sco5578 [103] & Q7BEC4 & 2.A.1.1.35 & $\begin{array}{l}\text { MFS major glucose uptake porters (two identical sequences at the AA level, } \\
\text { and having a single substitution on the NT level). }\end{array}$ \\
\hline MdrA; Sco4007 [104] & Q9ADP8 & 2.A.1.36.4 & Putative MDR transporter; may export hydrophobic cationic compounds. \\
\hline PitH1 and 2; Sco4138 and Sco1845 [105] & $\begin{array}{l}\text { Q9KZW3, } \\
\text { Q9RJ23 }\end{array}$ & $\begin{array}{l}\text { 2.A.20.1.5 } \\
\text { and } 6\end{array}$ & Two putative low-affinity inorganic phosphate $\left(P_{i}\right)$ uptake porters. \\
\hline $\begin{array}{l}\text { DasABC: Sco5232-4 (R, M, M). MsiK: } \\
\text { Sco4240 (C) [106] }\end{array}$ & $\begin{array}{l}\text { Q9K489-91, } \\
\text { Q9L0Q1 }\end{array}$ & 3.A.1.1.33 & DasABC/MsiK; system for the uptake of chitin-degradation products. \\
\hline $\begin{array}{l}\text { Agl3EFG porter (R, M, M; Sco7167-Sco7165 } \\
\text { [107]; Agl3K (C; unknown) }\end{array}$ & Q9FBS7-5 & 3.A.1.1.43 & $\begin{array}{l}\text { Sugar uptake porter; induced by trehalose and melibiose using a GntR } \\
\text { transcription factor. May use the MsiK ATPase [106]. }\end{array}$ \\
\hline $\begin{array}{l}\text { MalEFG; Sco2231-Sco2229 (R, M, M) [108]; } \\
\text { MalK (C) unknown. }\end{array}$ & $\begin{array}{l}\text { Q7AKP1, } \\
\text { Q9KZ07-8 }\end{array}$ & 3.A.1.1.44 & $\begin{array}{l}\text { Sugar uptake porter; involved in maltose and maltodextrin uptake. May use } \\
\text { the MsiK ATPase [106]. }\end{array}$ \\
\hline XylFGH. & O50503-5 & 3.A.1.2.24 & $\begin{array}{l}\text { Xylose uptake porter; transcriptionally regulated by a GntR-type protein, } \\
\text { ROK7B7. }\end{array}$ \\
\hline
\end{tabular}

XylG, Sco6010 (C; ATP-binding, no TMSs);

XylH, Sco6011 (M; 12 TMSs); [109]

Probable ABC peptide uptake porter: Sco5476-80 (M, R, M, C, C) [110]

O86571-5 3.A.1.5

Probably takes up a peptide involved in the regulation of sporulation and secondary metabolite production.

Sco5117-Sco5121 (R, M, M, C, C) [111]

Q9F353-49 3.A.1.5.35

Probable oligopeptide uptake porter.

BldKA-D and Sco5116; Sco5112-6 (M, R, M, C, C) [112]

Q93IU3-0; 3.A.1.5.36

BldKA-D and Sco5116; peptide uptake porter induced by S-

DesABC; Sco7499-8, Sco7400 (R, M-M, C) Q8CJS2 adenosylmethionine.

[113]

Q9L177-9 3.A.1.14.12 Desferrioxamine B uptake porter.

CchCDEF; Sco0497-4 (M, M, C, R) [113]

Q9RK09-12 3.A.1.14.13 Ferric iron-coelichelin uptake porter.

DesEFGH; Sco2780 (R), Sco1785-7 (C, M, M) Q9L07; [113]

Q9S215-3

3.A.1.14.22 Putative ferric iron-desferrioxamine E uptake porter.

SCIAB; Sco4359-60 (C, M) [114]

Q9F2Y8-7

3.A.1.105.13 ScIAB transporter; confers acyl depsipeptide (ADEP) resistance. ADEP has antibiotic activity.

RagAB; Sco4075-4 (C, M) [115]

Q7AKK4-5 3.A.1.105.14 RagAB exporter; involved in both aerial hyphae formation and sporulation.

SoxR regulon $A B C$ exporter; Sco7008 (M, C) [116]

Q9KZE5

3.A.1.106.9 Putative SoxR-regulated drug exporter; SoxR responds to extracellular redoxactive compounds such as actinorhodin.

AreABCD; Sco3956-9 (C, M, C', M') [117]

Q9ZBX6-3 3.A.1.146.1 Putative drug exporter; possibly specific for actinorhodin (ACT) and undecylprodigiosin (RED).

$H^{+}$-PPase; Sco3547 [118]

Q6BCL0

3.A.10.2.2 $\quad \mathrm{H}^{+}$-translocating inorganic pyrophosphatase.

MmrA; MXAN_5906 [119]

Q1CZY0

2.A.1.2.83

\section{M. xanthus}

TatABC; MXAN_2960, MXAN_5905-4, [120]

RfbAB; MXAN_4623-2 (M, C) [121]

Q1D854,

Q1CZY1-2

2.A.64.1.2 Twin arginine targeting protein translocase.

Q1D312-3 3.A.1.103.4 Putative lipopolysaccharide exporter.

AbcA; MXAN_1286 (M-C) [122]

Q1DCT0

3.A.1.106.10 AbcA; involved in molecular export; required for the autochemotactic process.

PilGHI; MXAN_5782-0 (R, C, M) [123]

O30384-6 3.A.1.144.5 Necessary for social motility, pilus assembly and pilus subunit (PilA) export.

\footnotetext{
${ }^{1} \mathrm{M}$ : Membrane component; C: cytoplasmic ATPase energizer; R: Extracytoplasmic solute receptor of an ABC transporter.
} 
In order to predict which membrane $(\mathrm{M})$ and cytoplasmic (C) ATPase proteins function with DesE, DesE was blasted against TCDB and brought up FhuD (3.A.1.14.7) as the best hit, the receptor for the ferric iron-hydroxamate porters of Staphylococcus aureus, FhuBCD,D2. FhuB, the membrane constituent, was then blasted against the Sco database and brought up Sco1785 and Sco0497 (CchC) as top hits. FhuC, the ATPase of the S. aureus porter, brought up Sco1787 and Sco0495 (CchE) as the top hits. Examination of the gene cluster containing Sco1785 and Sco1787 revealed that Sco1786 is a second membrane protein encoded in the same operon. However, no receptor was encoded in this operon or the surrounding gene cluster. We therefore propose that the characterized receptor, DesE, functions with Sco1785/Sco1786/Sco1787. We have designated this system DesEFGH, and it has been assigned TC\# 3.A.1.14.22 (see Table 11).

\section{Discussion}

Streptomyces coelicolor (Sco) and Myxococcus xanthus (Mxa) have genomes of about the same size, each present on a single chromosome. They have expanded genomes relative to almost all other prokaryotes with fully sequenced genomes. However, the numbers of integral membrane transport proteins encoded in these two genomes differ dramatically. We identified 658 in Sco, but only 355 in Mxa, a 93\% difference. Part of this difference reflects the total number of proteins encoded; Mxa has been reported to have $10 \%$ fewer protein-encoding genes than Sco. However, the primary explanation for the difference in numbers of transport proteins appears to come from studies aimed at determining the nature of the "expanded" gene sets. As reported by Goldman et al. [12], for Mxa, the increased genome size evidently resulted from extensive gene duplication and divergence relative to other bacteria of normal genome size, but of only certain functional types. More than 1500 duplications specific to the myxobacterial lineage were identified relative to other $\delta$-proteobacteria, and these represented $15.6 \%$ of the total genes. The amplified genes they identified dealt primarily with cell-cell signaling, small molecule sensing, and integrative transcriptional regulation [11]. For example, 97 serine/threonine protein kinases were identified in Mxa (44 were found in Sco), although other $\delta$-proteobacteria with "normal" sized genomes exhibit 0-3 such enzymes. Corresponding increases in some proteins (e.g., chaperones), but not other types of genes (e.g., transport systems), were generally observed in Mxa [12,36 and this study]. By contrast, in Sco, certain types of transporters were extensively amplified as shown here.

As for Mxa, there has been very considerable expansion of regulatory genes in Sco relative to other actinobacteria such as Mycobacterium tuberculosis and Corynebacterium diptheriae $[11,16]$. The total number of regulatory genes identified in Sco was 965 or $12.3 \%$, about the same as reported for Mxa [11,12]. However, in Sco, the numbers of transport and secreted proteins expanded relative to $M$. tuberculosis and $C$. diptheriae, although such extensive expansion was not observed for Mxa. These observations help to explain the differences in transport protein numbers in these two bacteria.

Mxa has a large repertoire of polyketide synthases, about twice that in Sco [12]. Since these enzymes are often in excess of 2,000 amino acyl residues in size, this fact may help to explain why the Mxa genome encodes fewer polypeptide chains than the Sco genome. In fact, the average protein size in Mxa is reported to be 376 aas/ polypeptide chain with approximately $90 \%$ of the genome coding for proteins [12]. In Sco, it is 330 aas/polypeptide chain with approximately $89 \%$ of the genome coding for proteins [11]. Thus, the increased number of proteins in Sco is compensated for by their decreased average size. It would be interesting to do a comparative study of protein sizes for the different functional types of proteins in a range of organisms to determine if this difference is specific or general.

Species of Streptomyces and Myxobacteria belong to two different bacterial phyla-the actinobacteria (high $\mathrm{G}+\mathrm{C}$ Gram-positive bacteria) and proteobacteria (Gram-negative $\delta$-proteobacteria) - and are therefore only very distantly related. However, (a) both are saprophytic microorganisms, (b) both encode multiple complex programs of differentiation, (c) both produce spores within multicellular structures (aerial mycelia and fruiting bodies, respectively), (d) both produce wide ranges of secondary metabolites including many pigments and macrolid antibiotics, (e) both communicate using numerous secreted small molecules, and (f) both degrade a wide range of extracellular macromolecules [2,5,14,86,125-129]. These two organisms have the most complex lifestyles of any bacteria currently under careful experimental scrutiny, and both have genomes that are larger than almost any other prokaryote whose genomes have been sequenced, thus accounting for their expanded genetic repertoire.

In view of these similarities, we compared the range of transport mechanisms and substrates used by these two developmental organisms. Such knowledge, we reasoned, would allow us to determine if they introduce developmental complexity along similar lines at the molecular level. Our studies led to the general conclusion that these two organisms have solved their metabolic needs and created programs of differentiation by entirely different means. For example, while Sco has a plethora of sugar, organic anion, and amino acid uptake systems of very specific types, Mxa has relatively few. In retrospect, this may be explained since myxobacteria are "micropredators," lysing other microorganisms which they use as food sources, while 
Streptomyces species may have evolved as beneficial, growth-promoting symbionts of other organisms $[126,128,129]$. It seems likely that the programs of development exhibited by these two organisms evolved independently, and the similarities reflect the limited numbers of options available. Other physiological similarities noted above possibly reflect a convergent evolutionary process, resulting from similarities in the habitats in which these organisms live.

Several surprises resulted from the analyses reported here. For example, Mxa has a member of the AAA family of nucleotide (ATP, ADP, $\mathrm{NAD}^{+}$, etc.) transporters, normally found only in obligatory intracellular parasites. It also has more (9) CorC-type putative $\mathrm{Mg}^{2+}$ transporters than we have encountered in any other organism. Mxa additionally has a $\mathrm{Ca}^{2+}$-ATPase, although such an enzyme was lacking in Sco where a $\mathrm{Ca}: \mathrm{H}^{+}$antiporter, lacking in Mxa, could be identified. It is known that both organisms rely on $\mathrm{Ca}^{2+}$ for developmental regulation [72-75]. We also discovered homologues of Spinster proteins, believed to be sphingosine-1-phosphate transporters in animals [53-55]. BLAST searches revealed that many bacteria have these proteins. Their substrates and functions may prove to be similar to those in animals since myxobacteria have been shown to have outer membrane sphingolipids [57].

Gram-negative bacteria have a number of transport systems that allow biogenesis, maintenance and function of the outer membranes of these organisms. These include the TolQ/R energizers of outer membrane receptor-mediated uptake of large molecules such as iron-siderophores and large vitamins, and they are known to function as energizers of gliding motility in Mxa [130]. They also include an outer membrane protein insertion porin apparatus (Bam or OmpIP systems; TC\#1.B.33) and the outer membrane lipopolysaccharide export porin complex 3 (LPS-EP systems; TC\#1.B.42). All of these systems were found in Mxa but could not be detected in Sco. Although Sco has an outer membrane of a very different composition [131], this observation implies that entirely different types of systems, serving the same functions, must exist in actinobacteria. It therefore seems clear that the comparative analyses reported here will open up new fields of microbial inquiry.

\section{Conclusions}

Analyses of transport proteins in two of the largest genome bacteria, both capable of sporulation and antibiotic production, one an actinobacterium and one a myxobacterium, revealed that these two organisms have evolved complexity via entirely different pathways. While both have amplified certain sets of transport protein-encoding genes, they differ in the degrees of amplification and the nature of the transporters amplified. The results provide insight into the evolution of prokaryotic complexity.

\section{Methods}

The proteomes of S. coelicolor strain A3(2) (Sco) and M. xanthus strain DK1622 (Mxa) were screened for homologues of all proteins contained in the Transporter Classification Database (TCDB; www.tcdb.org) as of September, 2011 using G-BLAST [132]. FASTA-formatted protein sequences of the completed genomes of Sco and Mxa were used. Each putative open-reading frame (ORF) was used as a query in the BLASTP software to search for homologous proteins in TCDB. The SEG low complexity filter was not used. In addition, each ORF was scanned with the HMMTOP 2.0 program [133] to predict the number of putative transmembrane segments (TMSs). The WHAT program [134] was used to resolve the differences in the numbers of TMSs between Sco proteins, Mxa proteins, and their TCDB homologues. A cut-off value of 0.001 was used with the G-BLAST program so proteins retrieved with larger values (greater sequence divergence) were not recorded. After analysis of these proteins was conducted, proteins with e-values between 0.1 and 0.001 were retrieved, and the more distant homologues to TC entries were identified. Proteins with 0 predicted TMSs were eliminated so that only integral membrane proteins (primarily multi-spanning membrane proteins) were retrieved. Some single TMS proteins, including many extracytoplasmic solute binding receptors of $\mathrm{ABC}$ transport systems, were often predicted to lack a TMS and therefore were not included in our study.

Candidate proteins were subsequently examined in greater detail to estimate their substrate specificities. On the basis of the numbers and locations of TMSs, as well as degrees of sequence similarities with entries of known function in TCDB, transport proteins were classified into families and subfamilies of homologous transporters according to the classification system presented in TCDB [17,18]. Regions of sequence similarity were examined to ensure that homology was in transmembrane regions and not in hydrophilic domains. Proteins encoded within single operons were often identified in order to gain evidence for multicomponent systems and to help deduce probable functions. Operon analyses were performed for candidate proteins with assigned or unassigned transport functions.

The substrate specificities of particular homologues identified in the sequenced genomes were sometimes predicted based on homology to functionally characterized genes and from their genomic context. Assignment to a family or subfamily within the TC system often allows prediction of substrate type with confidence [13,20,135-137]. When an expected transport protein constituent of a multi-component transport system could 
not be identified with BLASTP, tBLASTn was performed because such expected proteins are sometimes undetectable by BLASTP due to sequencing errors, sequence divergence, or pseudogene formation.

Transport proteins thus obtained were systematically analyzed for unusual properties using published [132] and unpublished in-house software. Unusual properties can result from events such as genetic deletion and fusion, sometimes resulting in the gain or loss of extra domains or the generation of multifunctional proteins. Such results can be reflective of the actual protein sequence, but can also be artifactual, due to sequencing errors or incorrect initiation codon assignment. In the latter cases, but not the former, the protein sequences were either corrected when possible or eliminated from our study.

This theoretical bioinformatics study does not contain any experimental research that requires the approval of an ethics committee.

\section{Additional files}

Additional file 1: Table S1. Sco transport proteins. Detailed description of Sco transport proteins and their homologues in TCDB, including comparison scores obtained via G-Blast and GSAT, substrate, substrate class, organism, phylum, and organismal domain. Proteins are organized from lowest to highest TC\#.

Additional file 2: Table S2. Mxa transport proteins. Detailed description of Mxa transport proteins and their homologues in TCDB, including comparison scores obtained via G-Blast and GSAT, substrate, substrate class, organism, phylum, and organismal domain. Proteins are organized from lowest to highest TC\#.

Additional file 3: Table S3. Chromosomal distribution of Sco transporters. Sco transport proteins distributed by chromosomal arms and core.

\section{Competing interests}

The authors are not aware of any affiliations, memberships, funding, or financial holdings that might be perceived as affecting the objectivity of this review.

\section{Authors' contributions}

Conceived and designed the experiments MHS; Performed the experiments IG, GHN, DCY, PCGP; Analyzed the data: IG, GHN, DCY, AV; Contributed reagents/materials/analysis tools VSR; Wrote the paper IG, GHN, DCY, MHS. All authors read and approved the final manuscript.

\section{Acknowledgements}

We thank Carl Welliver and Maksim Shlykov for valuable assistance in the preparation of this manuscript. This work was supported by NIH Grant GM077402.

Received: 19 July 2013 Accepted: 20 November 2013 Published: 5 December 2013

\section{References}

1. de Hoon MJ, Eichenberger P, Vitkup D: Hierarchical evolution of the bacterial sporulation network. Curr Biol 2010, 20(17):R735-745.

2. Flardh K, Buttner MJ: Streptomyces morphogenetics: dissecting differentiation in a filamentous bacterium. Nat Rev Microbiol 2009, 7(1):36-49.

3. Gogolewski RP, Mackintosh JA, Wilson SC, Chin JC: Immunodominant antigens of zoospores from ovine isolates of Dermatophilus congolensis. Vet Microbiol 1992, 32(3-4):305-318.
4. Setubal JC, dos Santos P, Goldman BS, Ertesvag H, Espin G, Rubio LM, Valla S, Almeida NF, Balasubramanian D, Cromes L, et al: Genome sequence of Azotobacter vinelandii, an obligate aerobe specialized to support diverse anaerobic metabolic processes. J Bacteriol 2009, 191(14):4534-4545

5. Kaiser D, Robinson M, Kroos L: Myxobacteria, polarity, and multicellular morphogenesis. Cold Spring Harb Perspect Biol 2010, 2(8):a000380.

6. Sarma TA, Ahuja G, Khattar Jl: Nutrient stress causes akinete differentiation in cyanobacterium Anabaena torulosa with concomitant increase in nitrogen reserve substances. Folia Microbiol (Praha) 2004, 49(5):557-561.

7. Higgins D, Dworkin J: Recent progress in bacillus subtilis sporulation. FEMS Microbiol Rev 2012, 36(1):131-148.

8. Perez J, Munoz-Dorado J, Brana AF, Shimkets LJ, Sevillano L, Santamaria Rl: Myxococcus xanthus induces actinorhodin overproduction and aerial mycelium formation by Streptomyces coelicolor. Microb Biotechnol 2011, 4(2):175-183.

9. Diez J, Martinez JP, Mestres J, Sasse F, Frank R, Meyerhans A: Myxobacteria: natural pharmaceutical factories. Microb Cell Fact 2012, 11:52.

10. de Lima Procopio RE, da Silva IR, Martins MK, de Azevedo JL, de Araujo JM: Antibiotics produced by Streptomyces. Braz J Infect Dis 2012, 16(5):466-71.

11. Bentley SD, Chater KF, Cerdeno-Tarraga AM, Challis GL, Thomson NR, James KD, Harris DE, Quail MA, Kieser H, Harper D, et al: Complete genome sequence of the model actinomycete Streptomyces coelicolor $A 3(2)$. Nature 2002, 417(6885):141-147.

12. Goldman BS, Nierman WC, Kaiser D, Slater SC, Durkin AS, Eisen JA, Ronning CM, Barbazuk WB, Blanchard M, Field C, et al: Evolution of sensory complexity recorded in a myxobacterial genome. Proc Natl Acad Sci USA 2006, 103(41):15200-15205.

13. Saier MH Jr: A functional-phylogenetic classification system for transmembrane solute transporters. Microbiol Mol Biol Rev 2000, 64(2):354-411.

14. Martin JF, Sola-Landa A, Santos-Beneit F, Fernandez-Martinez LT, Prieto C, Rodriguez-Garcia A: Cross-talk of global nutritional regulators in the control of primary and secondary metabolism in Streptomyces. Microb Biotechnol 2011, 4(2):165-174.

15. Chater KF, Biro S, Lee KJ, Palmer T, Schrempf H: The complex extracellular biology of Streptomyces. FEMS Microbiol Rev 2010, 34(2):171-198.

16. Youm J, Saier MH Jr: Comparative analyses of transport proteins encoded within the genomes of mycobacterium tuberculosis and mycobacterium leprae. Biochim Biophys Acta 2012, 1818(3):776-797.

17. Saier MH Jr, Tran CV, Barabote RD: TCDB: the transporter classification database for membrane transport protein analyses and information. Nucleic Acids Res 2006, 34(Database issue):D181-186.

18. Saier MH Jr, Yen MR, Noto K, Tamang DG, Elkan C: The transporter classification database: recent advances. Nucleic Acids Res 2009, 37(Database issue):D274-278.

19. Saier MH Jr: Protein secretion and membrane insertion systems in gram-negative bacteria. J Membr Biol 2006, 214(2):75-90.

20. Busch W, Saier MH Jr: The transporter classification (TC) system, 2002. Crit Rev Biochem Mol Biol 2002, 37(5):287-337.

21. Riess FG, Lichtinger T, Cseh R, Yassin AF, Schaal KP, Benz R: The cell wall porin of Nocardia farcinica: biochemical identification of the channel-forming protein and biophysical characterization of the channel properties. Mol Microbiol 1998, 29(1):139-150.

22. Lichtinger T, Riess FG, Burkovski A, Engelbrecht F, Hesse D, Kratzin HD, Kramer R, Benz R: The low-molecular-mass subunit of the cell wall channel of the Gram-positive Corynebacterium glutamicum. Immunological localization, cloning and sequencing of its gene porA Eur J Biochem 2001, 268(2):462-469.

23. Ziegler $K$, Benz $R$, Schulz GE: A putative alpha-helical porin from Corynebacterium glutamicum. J Mol Biol 2008, 379(3):482-491.

24. Niederweis M: Mycobacterial porins-new channel proteins in unique outer membranes. Mol Microbiol 2003, 49(5):1167-1177.

25. Niederweis M: Nutrient acquisition by mycobacteria. Microbiology 2008 , 154(Pt 3):679-692.

26. Chater KF: Genetic regulation of secondary metabolic pathways in Streptomyces. Ciba Found Symp 1992, 171:144-156. discussion 156-162.

27. Williamson NR, Fineran PC, Leeper FJ, Salmond GP: The biosynthesis and regulation of bacterial prodiginines. Nat Rev Microbiol 2006, 4(12):887-899. 
28. Wang B, Dukarevich M, Sun El, Yen MR, Saier MH Jr: Membrane porters of ATP-binding cassette transport systems are polyphyletic. J Membr Biol 2009, 231(1):1-10.

29. Saier MH Jr: Tracing pathways of transport protein evolution. Mol Microbiol 2003, 48(5):1145-1156.

30. Paulsen IT, Beness AM, Saier MH Jr: Computer-based analyses of the protein constituents of transport systems catalysing export of complex carbohydrates in bacteria. Microbiology 1997, 143(Pt 8):2685-2699.

31. Whitfield C: Biosynthesis and assembly of capsular polysaccharides in Escherichia coli. Annu Rev Biochem 2006, 75:39-68.

32. Ellermeier CD, Hobbs EC, Gonzalez-Pastor JE, Losick R: A three-protein signaling pathway governing immunity to a bacterial cannibalism toxin. Cell 2006, 124(3):549-559.

33. Bhat S, Zhu X, Patel RP, Orlando R, Shimkets L: Identification and localization of Myxococcus xanthus porins and lipoproteins. PLoS One 2011, 6(11):e27475

34. Bretscher AP, Kaiser D: Nutrition of Myxococcus xanthus, a fruiting myxobacterium. J Bacterio/ 1978, 133(2):763-768.

35. Konovalova A, Petters T, Sogaard-Andersen L: Extracellular biology of Myxococcus xanthus. FEMS Microbiol Rev 2010, 34(2):89-106.

36. Karlin S, Brocchieri L, Mrazek J, Kaiser D: Distinguishing features of delta-proteobacterial genomes. Proc Natl Acad Sci USA 2006, 103(30):11352-11357.

37. Chang AB, Lin R, Keith Studley W, Tran CV, Saier MH Jr: Phylogeny as a guide to structure and function of membrane transport proteins. Mol Membr Biol 2004, 21(3):171-181.

38. Lam VH, Lee JH, Silverio A, Chan H, Gomolplitinant KM, Povolotsky TL, Orlova E, Sun El, Welliver CH, Saier MH Jr: Pathways of transport protein evolution: recent advances. Biol Chem 2011, 392(1-2):5-12.

39. Liebeskind BJ, Hillis DM, Zakon HH: Phylogeny unites animal sodium leak channels with fungal calcium channels in an ancient, voltage-insensitive clade. Mol Biol Evol 2012, 29(12):3613-6.

40. Raja M: The potassium channel KcsA: a model protein in studying membrane protein oligomerization and stability of oligomeric assembly? Arch Biochem Biophys 2011, 510(1):1-10.

41. Danielson JA, Johanson U: Phylogeny of major intrinsic proteins. Adv Exp Med Biol 2010, 679:19-31.

42. Booth IR, Blount P: The MscS and MscL Families of Mechanosensitive channels act as microbial emergency release valves. J Bacterio/ 2012, 194(18):4802-4809.

43. Barabote RD, Rendulic S, Schuster SC, Saier MH Jr: Comprehensive analysis of transport proteins encoded within the genome of Bdellovibrio bacteriovorus. Genomics 2007, 90(4):424-446.

44. Maier RV, Hahnel GB, Pohlman TH: Endotoxin requirements for alveolar macrophage stimulation. J Trauma 1990, 30(12 Suppl):S49-57.

45. Hagan $\mathrm{CL}$, Silhavy $\mathrm{TJ}$ : Kahne D: beta-Barrel membrane protein assembly by the Bam complex. Annu Rev Biochem 2011, 80:189-210.

46. Freinkman E, Okuda S, Ruiz N, Kahne D: Regulated assembly of the transenvelope protein complex required for lipopolysaccharide export. Biochemistry 2012, 51(24):4800-4806.

47. Chng SS, Xue M, Garner RA, Kadokura H, Boyd D, Beckwith J, Kahne D: Disulfide rearrangement triggered by translocon assembly controls lipopolysaccharide export. Science 2012, 337(6102):1665-8

48. Pao SS, Paulsen IT, Saier MH Jr: Major facilitator superfamily. Microbiol Mol Biol Rev 1998, 62(1):1-34

49. Reddy VS, Shlykov MA, Castillo R, Sun El, Saier MH Jr: The major facilitator superfamily (MFS) revisited. Febs J 2012, 279(11):2022-2035.

50. Winkler HH, Neuhaus HE: Non-mitochondrial ATP transport. Trends Biochem Sci 1999, 24(2):64-68.

51. Haferkamp I, Schmitz-Esser S, Wagner M, Neigel N, Horn M, Neuhaus HE: Tapping the nucleotide pool of the host: novel nucleotide carrier proteins of Protochlamydia amoebophila. Mol Microbiol 2006, 60(6):1534-1545

52. Zhang Y, Ducret A, Shaevitz J, Mignot T: From individual cell motility to collective behaviors: insights from a prokaryote, Myxococcus xanthus. FEMS Microbiol Rev 2012, 36(1):149-164.

53. Nijnik A, Clare S, Hale C, Chen J, Raisen C, Mottram L, Lucas M, Estabel J,

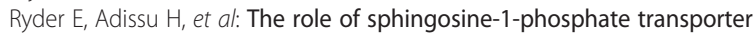
Spns2 in immune system function. J Immunol 2012, 189(1):102-111.

54. Fukuhara S, Simmons S, Kawamura S, Inoue A, Orba Y, Tokudome T, Sunden Y, Arai Y, Moriwaki K, Ishida J, et al: The sphingosine-1-phosphate transporter Spns2 expressed on endothelial cells regulates lymphocyte trafficking in mice. J Clin Invest 2012, 122(4):1416-1426.

55. Yanagisawa H, Miyashita T, Nakano Y, Yamamoto D: HSpin1, a transmembrane protein interacting with $\mathrm{BCl}-2 / \mathrm{BCl}-\mathrm{xL}$, induces a caspase-independent autophagic cell death. Cell Death Differ 2003, 10(7):798-807

56. Vastermark A, Jacobsson JA, Johansson A, Fredriksson R, Gyllensten U, Schioth HB: Polymorphisms in sh2b1 and spns1 loci are associated with triglyceride levels in a healthy population in northern Sweden. J Genet 2012, 91(2):237-240.

57. Keck M, Gisch N, Moll H, Vorholter FJ, Gerth K, Kahmann U, Lissel M, Lindner B, Niehaus K, Holst O: Unusual outer membrane lipid composition of the gram-negative, lipopolysaccharide-lacking myxobacterium Sorangium cellulosum So ce56. J Biol Chem 2011, 286(15):12850-12859.

58. Jack DL, Paulsen IT, Saier MH: The amino acid/polyamine/organocation (APC) superfamily of transporters specific for amino acids, polyamines and organocations. Microbiology 2000, 146(Pt 8):1797-1814.

59. Wong FH, Chen JS, Reddy V, Day JL, Shlykov MA, Wakabayashi ST, Saier MH Jr The amino acid-polyamine-organocation superfamily. J Mol Microbiol Biotechnol 2012, 22(2):105-113.

60. Haney CJ, Grass G, Franke S, Rensing C: New developments in the understanding of the cation diffusion facilitator family. J Ind Microbiol Biotechnol 2005, 32(6):215-226.

61. Hantke K: Bacterial zinc uptake and regulators. Curr Opin Microbiol 2005, 8(2):196-202.

62. Blair JM, Piddock LJ: Structure, function and inhibition of RND efflux pumps in Gram-negative bacteria: an update. Curr Opin Microbiol 2009, 12(5):512-519.

63. Tseng TT, Gratwick KS, Kollman J, Park D, Nies DH, Goffeau A, Saier MH Jr: The RND permease superfamily: an ancient, ubiquitous and diverse family that includes human disease and development proteins. J Mol Microbiol Biotechnol 1999, 1(1):107-125.

64. Moraleda-Munoz A, Perez J, Extremera AL, Munoz-Dorado J: Differential regulation of six heavy metal efflux systems in the response of Myxococcus xanthus to copper. App/ Environ Microbiol 2010, 76(18):6069-6076.

65. Ardourel M, Demont N, Debelle F, Maillet F, de Billy F, Prome JC, Denarie J, Truchet G: Rhizobium meliloti lipooligosaccharide nodulation factors: different structural requirements for bacterial entry into target root hair cells and induction of plant symbiotic developmental responses. Plant Cell 1994, 6(10):1357-1374.

66. Tsukazaki T, Mori H, Echizen Y, Ishitani R, Fukai S, Tanaka T, Perederina A, Vassylyev DG, Kohno T, Maturana AD, et al: Structure and function of a membrane component SecDF that enhances protein export. Nature 2011, 474(7350):235-238.

67. Pasca MR, Guglierame P, De Rossi E, Zara F, Riccardi G: MmpL7 gene of Mycobacterium tuberculosis is responsible for isoniazid efflux in Mycobacterium smegmatis. Antimicrob Agents Chemother 2005, 49(11):4775-4777.

68. Doughty DM, Coleman ML, Hunter RC, Sessions AL, Summons RE, Newman DK: The RND-family transporter, $\mathrm{HpnN}$, is required for hopanoid localization to the outer membrane of Rhodopseudomonas palustris TIE-1. Proc Natl Acad Sci U S A 2011, 108(45):E1045-1051.

69. Jack DL, Yang NM, Saier MH Jr: The drug/metabolite transporter superfamily. Eur J Biochem 2001, 268(13):3620-3639.

70. Dalbey RE, Wang P, Kuhn A: Assembly of bacterial inner membrane proteins. Annu Rev Biochem 2011, 80:161-187.

71. Saller MJ, Fusetti F, Driessen AJ: Bacillus subtilis SpollIJ and YqjG function in membrane protein biogenesis. J Bacterio/ 2009, 191(21):6749-6757.

72. Otani M, Kozuka S, Xu C, Umezawa C, Sano K, Inouye S: Protein W, a spore-specific protein in Myxococcus xanthus, formation of a large electron-dense particle in a spore. Mol Microbiol 1998, 30(1):57-66.

73. Kuner JM, Kaiser D: Fruiting body morphogenesis in submerged cultures of Myxococcus xanthus. J Bacteriol 1982, 151(1):458-461.

74. Kim YM, Kim JH: Formation and dispersion of mycelial pellets of Streptomyces coelicolor A3(2). J Microbiol 2004, 42(1):64-67.

75. Elizarov SM, Danilenko VN: Multiple phosphorylation of membrane-associated calcium-dependent protein serine/threonine kinase in Streptomyces fradiae. FEMS Microbiol Lett 2001, 202(1):135-138 
76. Padan $\mathrm{E}$, Bibi $\mathrm{E}$, Ito $\mathrm{M}$, Krulwich TA: Alkaline $\mathrm{pH}$ homeostasis in bacteria: new insights. Biochim Biophys Acta 2005, 1717(2):67-88.

77. Yen MR, Tseng YH, Nguyen EH, Wu LF, Saier MH Jr: Sequence and phylogenetic analyses of the twin-arginine targeting (Tat) protein export system. Arch Microbiol 2002, 177(6):441-450

78. Palmer T, Berks BC: The twin-arginine translocation (Tat) protein export pathway. Nat Rev Microbiol 2012, 10(7):483-496.

79. Hvorup RN, Winnen B, Chang AB, Jiang Y, Zhou XF, Saier MH Jr: The multidrug/oligosaccharidyl-lipid/polysaccharide (MOP) exporter superfamily. Eur J Biochem 2003, 270(5):799-813.

80. Ruiz N: Bioinformatics identification of MurJ (MviN) as the peptidoglycan lipid II flippase in Escherichia coli. Proc Natl Acad Sci U S A 2008, 105(40):15553-15557.

81. Vasudevan P, McElligott J, Attkisson C, Betteken M, Popham DL: Homologues of the Bacillus subtilis SpoVB protein are involved in cell wall metabolism. J Bacterio/ 2009, 191(19):6012-6019.

82. Fay A, Dworkin J: Bacillus subtilis homologs of MviN (MurJ), the putative Escherichia coli lipid II flippase, are not essential for growth. J Bacteriol 2009, 191(19):6020-6028.

83. Mohammadi T, van Dam V, Sijbrandi R, Vernet T, Zapun A, Bouhss A, Diepeveen-de Bruin M, Nguyen-Disteche M, de Kruijff B, Breukink E: Identification of FtsW as a transporter of lipid-linked cell wall precursors across the membrane. Embo J 2011, 30(8):1425-1432.

84. Hu W, Wang J, McHardy I, Lux R, Yang Z, Li Y, Shi W: Effects of exopolysaccharide production on liquid vegetative growth, stress survival, and stationary phase recovery in Myxococcus xanthus. J Microbiol 2012, 50(2):241-248.

85. Garza AG, Harris BZ, Pollack JS, Singer M: The asgE locus is required for cell-cell signalling during Myxococcus xanthus development. Mol Microbiol 2000, 35(4):812-824

86. McCormick JR, Flardh K: Signals and regulators that govern Streptomyces development. FEMS Microbiol Rev 2012, 36(1):206-231.

87. Atkinson S, Williams P: Quorum sensing and social networking in the microbial world. J R Soc Interface 2009, 6(40):959-978.

88. Rettner RE, Saier MH Jr: The autoinducer-2 exporter superfamily. J Mol Microbiol Biotechnol 2010, 18(4):195-205.

89. Shlykov MA, Zheng WH, Chen JS, Saier MH Jr: Bioinformatic characterization of the 4-Toluene Sulfonate Uptake Permease (TSUP) family of transmembrane proteins. Biochim Biophys Acta 2012, 1818(3):703-717.

90. Thever MD, Saier MH Jr: Bioinformatic characterization of p-type ATPases encoded within the fully sequenced genomes of 26 eukaryotes. J Membr Biol 2009, 229(3):115-130.

91. Chan H, Babayan V, Blyumin E, Gandhi C, Hak K, Harake D, Kumar K, Lee P, Li TT, Liu HY, et al: The P-type ATPase superfamily. J Mol Microbiol Biotechnol 2010, 19(1-2):5-104.

92. Hassani BK, Astier C, Nitschke W, Ouchane S: CtpA, a copper-translocating P-type ATPase involved in the biogenesis of multiple copper-requiring enzymes. J Biol Chem 2010, 285(25):19330-19337.

93. Campos M, Cisneros DA, Nivaskumar M, Francetic O: The type II secretion system - a dynamic fiber assembly nanomachine. Res Microbiol 2013, 164(6):545-555.

94. Chatterjee S, Chaudhury S, McShan AC, Kaur K, De Guzman RN: Structure and biophysics of type III secretion in bacteria. Biochemistry 2013, 52(15):2508-2517.

95. Barabote RD, Saier MH Jr: Comparative genomic analyses of the bacterial phosphotransferase system. Microbiol Mol Biol Rev 2005, 69(4):608-634

96. Van Baak DA, Hollberg L: Proposed sum-and-difference method for optical-frequency measurement in the near infrared. Opt Lett 1994, 19(19):1586-1588.

97. Nothaft H, Parche S, Kamionka A, Titgemeyer F: In vivo analysis of $\mathrm{HPr}$ reveals a fructose-specific phosphotransferase system that confers high-affinity uptake in Streptomyces coelicolor. J Bacteriol 2003, 185(3):929-937.

98. Nothaft H, Dresel D, Willimek A, Mahr K, Niederweis M, Titgemeyer F: The phosphotransferase system of Streptomyces coelicolor is biased for $\mathrm{N}$-acetylglucosamine metabolism. J Bacteriol 2003, 185(23):7019-7023.

99. Rigali S, Nothaft H, Noens EE, Schlicht M, Colson S, Muller M, Joris B, Koerten HK, Hopwood DA, Titgemeyer F, et al: The sugar phosphotransferase system of Streptomyces coelicolor is regulated by the GntR-family regulator DasR and links N-acetylglucosamine metabolism to the control of development. Mol Microbiol 2006, 61(5):1237-1251

100. Colson S, van Wezel GP, Craig M, Noens EE, Nothaft H, Mommaas AM, Titgemeyer F, Joris B, Rigali S: The chitobiose-binding protein, DasA, acts as a link between chitin utilization and morphogenesis in Streptomyces coelicolor. Microbiology 2008, 154(Pt 2):373-382.

101. Kelley DR, Liu B, Delcher AL, Pop M, Salzberg SL: Gene prediction with Glimmer for metagenomic sequences augmented by classification and clustering. Nucleic Acids Res 2012, 40(1):e9.

102. Wang CX, Ge HX, Hou XP, Li YQ: Roles of larger conductance mechanosensitive channels (MscL) in sporulation and Act secretion in Streptomyces coelicolor. J Basic Microbiol 2007, 47(6):518-524.

103. van Wezel GP, Mahr K, Konig M, Traag BA, Pimentel-Schmitt EF, Willimek A, Titgemeyer F: GlcP constitutes the major glucose uptake system of Streptomyces coelicolor A3(2). Mol Microbiol 2005, 55(2):624-636.

104. Hayashi T, Tanaka Y, Sakai N, Okada U, Yao M, Watanabe N, Tamura T, Tanaka I: SCO4008, a putative TetR transcriptional repressor from streptomyces coelicolor $A 3(2)$, regulates transcription of sco4007 by multidrug recognition. J Mol Biol 2013, 425(18):3289-3300.

105. Santos-Beneit F, Rodriguez-Garcia A, Franco-Dominguez E, Martin JF: Phosphate-dependent regulation of the low- and high-affinity transport systems in the model actinomycete Streptomyces coelicolor. Microbiology 2008, 154(Pt 8):2356-2370.

106. Saito A, Ebise H, Orihara Y, Murakami S, Sano Y, Kimura A, Sugiyama Y, Ando A, Fujii T, Miyashita K: Enzymatic and genetic characterization of the DasD protein possessing $\mathrm{N}$-acetyl-beta-d-glucosaminidase activity in Streptomyces coelicolor A3(2). FEMS Microbiol Lett 2013, 340(1):33-40.

107. Hillerich B, Westpheling J: A new GntR family transcriptional regulator in Streptomyces coelicolor is required for morphogenesis and antibiotic production and controls transcription of an $A B C$ transporter in response to carbon source. J Bacteriol 2006, 188(21):7477-7487.

108. van Wezel GP, White J, Bibb MJ, Postma PW: The malEFG gene cluster of Streptomyces coelicolor A3(2): characterization, disruption and transcriptional analysis. Mol Gen Genet 1997, 254(5):604-608.

109. Swiatek MA, Gubbens J, Bucca G, Song E, Yang YH, Laing E, Kim BG, Smith CP, van Wezel GP: The ROK family regulator Rok7B7 pleiotropically affects xylose utilization, carbon catabolite repression, and antibiotic production in Streptomyces coelicolor. J Bacteriol 2013, 195(6):1236-1248.

110. Shin SK, Park HS, Kwon HJ, Yoon HJ, Suh JW: Genetic characterization of two S-adenosylmethionine-induced $A B C$ transporters reveals their roles in modulations of secondary metabolism and sporulation in Streptomyces coelicolor M145. J Microbiol Biotechnol 2007, 17(11):1818-1825.

111. Akanuma G, Ueki M, Ishizuka M, Ohnishi Y, Horinouchi S: Control of aerial mycelium formation by the BldK oligopeptide $A B C$ transporter in Streptomyces griseus. FEMS Microbiol Lett 2011, 315(1):54-62.

112. Chavez A, Forero A, Sanchez M, Rodriguez-Sanoja R, Mendoza-Hernandez G, Servin-Gonzalez L, Sanchez B, Garcia-Huante Y, Rocha D, Langley E, et al: Interaction of SCO2127 with BldKB and its possible connection to carbon catabolite regulation of morphological differentiation in Streptomyces coelicolor. Appl Microbiol Biotechnol 2011, 89(3):799-806.

113. Barona-Gomez F, Lautru S, Francou FX, Leblond P, Pernodet JL, Challis GL: Multiple biosynthetic and uptake systems mediate siderophore-dependent iron acquisition in Streptomyces coelicolor A3(2) and Streptomyces ambofaciens ATCC 23877. Microbiology 2006, 152(Pt 11):3355-3366.

114. Gominet M, Seghezzi N, Mazodier P: Acyl depsipeptide (ADEP) resistance in Streptomyces. Microbiology 2011, 157(Pt 8):2226-2234.

115. San Paolo S, Huang J, Cohen SN, Thompson CJ: Rag genes: novel components of the RamR regulon that trigger morphological differentiation in Streptomyces coelicolor. Mol Microbiol 2006, 61(5):1167-1186.

116. Shin $J H$, Singh AK, Cheon DJ, Roe JH: Activation of the SoxR regulon in Streptomyces coelicolor by the extracellular form of the pigmented antibiotic actinorhodin. J Bacteriol 2011, 193(1):75-81.

117. Lee SK, Mo S, Suh JW: An ABC transporter complex containing S-adenosylmethionine (SAM)-induced ATP-binding protein is involved in antibiotics production and SAM signaling in Streptomyces coelicolor M145. Biotechnol Lett 2012, 34(10):1907-1914.

118. Hirono M, Nakanishi Y, Maeshima M: Identification of amino acid residues participating in the energy coupling and proton transport of 
Streptomyces coelicolor A3(2) $\mathrm{H}+-$ pyrophosphatase. Biochim Biophys Acta 2007, 1767(12):1401-1411.

119. Kimura Y, Ishida S, Matoba H, Okahisa N: A Myxococcus xanthus rppA-mmrA double mutant exhibits reduced uptake of amino acids and tolerance of some antimicrobials. FEMS Microbiol Lett 2004, 238(1):145-150.

120. Kimura Y, Saiga H, Hamanaka H, Matoba H: Myxococcus xanthus twinarginine translocation system is important for growth and development. Arch Microbiol 2006, 184(6):387-396.

121. Guo D, Bowden MG, Pershad R, Kaplan HB: The Myxococcus xanthus rfbABC operon encodes an ATP-binding cassette transporter homolog required for $\mathrm{O}$-antigen biosynthesis and multicellular development. J Bacteriol 1996, 178(6):1631-1639.

122. Ward MJ, Mok KC, Astling DP, Lew H, Zusman DR: An ABC transporter plays a developmental aggregation role in Myxococcus xanthus. J Bacteriol 1998, 180(21):5697-5703.

123. Wu SS, Wu J, Cheng YL, Kaiser D: The pilH gene encodes an ABC transporter homologue required for type IV pilus biogenesis and social gliding motility in Myxococcus xanthus. Mol Microbiol 1998, 29(5):1249-1261.

124. Kuan G, Dassa E, Saurin W, Hofnung M, Saier MH Jr: Phylogenetic analyses of the ATP-binding constituents of bacterial extracytoplasmic receptor-dependent ABC-type nutrient uptake permeases. Res Microbiol 1995, 146(4):271-278.

125. Zhou Z, Gu J, Du YL, Li YQ, Wang Y: The -omics Era- toward a systemslevel understanding of Streptomyces. Curr Genomics 2011, 12(6):404-416.

126. Seipke RF, Kaltenpoth M, Hutchings MI: Streptomyces as symbionts: an emerging and widespread theme? FEMS Microbiol Rev 2012, 36(4):862-876.

127. Whitworth DE: Myxobacterial vesicles: death at a distance? Adv Appl Microbiol 2011, 75:1-31.

128. Li Y, Muller R: Non-modular polyketide synthases in myxobacteria. Phytochemistry 2009, 70(15-16):1850-1857.

129. Berleman JE, Kirby JR: Deciphering the hunting strategy of a bacterial wolfpack. FEMS Microbiol Rev 2009, 33(5):942-957.

130. Youderian P, Burke N, White DJ, Hartzell PL: Identification of genes required for adventurous gliding motility in Myxococcus xanthus with the transposable element mariner. Mol Microbiol 2003, 49(2):555-570.

131. Saier MH Jr: Structure and evolution of prokaryotic cell types. Microbe 2008, 3(7):6.

132. Reddy VS, Saier MH Jr: BioV Suite-a collection of programs for the study of transport protein evolution. Febs J 2012, 279(11):2036-2046.

133. Ikeda M, Arai M, Lao DM, Shimizu T: Transmembrane topology prediction methods: a re-assessment and improvement by a consensus method using a dataset of experimentally-characterized transmembrane topologies. In Silico Biol 2002, 2(1):19-33.

134. Zhai Y, Saier MH Jr: A web-based program (WHAT) for the simultaneous prediction of hydropathy, amphipathicity, secondary structure and transmembrane topology for a single protein sequence. J Mol Microbiol Biotechnol 2001, 3(4):501-502.

135. Harvat EM, Zhang YM, Tran CV, Zhang Z, Frank MW, Rock CO, Saier MH Jr: Lysophospholipid flipping across the Escherichia coli inner membrane catalyzed by a transporter (LpIT) belonging to the major facilitator superfamily. J Biol Chem 2005, 280(12):12028-12034.

136. Felce J, Saier MH Jr: Carbonic anhydrases fused to anion transporters of the SulP family: evidence for a novel type of bicarbonate transporter. J Mol Microbiol Biotechnol 2004, 8(3):169-176.

137. Zhang Z, Feige JN, Chang AB, Anderson IJ, Brodianski VM, Vitreschak AG, Gelfand MS, Saier MH Jr: A transporter of Escherichia coli specific for $\mathrm{L}$ - and D-methionine is the prototype for a new family within the $A B C$ superfamily. Arch Microbiol 2003, 180(2):88-100.

\section{Submit your next manuscript to BioMed Central and take full advantage of:}

- Convenient online submission

- Thorough peer review

- No space constraints or color figure charges

- Immediate publication on acceptance

- Inclusion in PubMed, CAS, Scopus and Google Scholar

- Research which is freely available for redistribution 